\title{
Das habituelle Absterben der Frucht und die künstliche Friihgeburt,
}

mit Bemerkungen zur Pathologie der Placenta und des Nabelstranges.

Von

Dr. Gerhard Leopold,

Privatdocent der Gynäkologie an der Universität Leipzig.

Unter den Indicationen zur künstlichen Frühgeburt steht die der Beckenenge mit Recht voran. Ihr Werth hat erst in der jüngsten Zeit noch von Spiegelberg, Litzmann, Dohrn u. A. die eingehendste Besprechung erfahren. Weit weniger dagegen wissen wir vom Werthe der beiden anderen Indicationen zur Frühgeburt, nämlich vom habituellen Absterben der Frucht und krankhaften Zuständen der Mutter, welche das Leben derselben in Gefahr bringen. Ich darf darum wohl an der Hand eines genau beobachteten Falles von künstlicher Frühgeburt wegen habituellen Absterbens der Frucht um so mehr Gelegenheit nehmen, auf den Werth dieser Operationsmethode bei dem fraglichen Zustande näher einzugehen und dieselbe einer Kritik zu unterwerfen, als die Ansichten der Autoren über den habituellen Fruchttod als Anzeige zur Einleitung der Frühgeburt bis in die jüngste Zeit zum Theil diametral entgegengesetzte gewesen sind. Es werden hierbei eine Reihe von Beobachtungen mit zur Sprache kommen, die hinlänglich zeigen, über wieviele Punkte betreffs des intrauterinen Lebens der Frucht und der Todesursachen derselben wir noch ganz im Unklaren sind. Wenn ich aber mit nur ein e m einschlagenden selbst beobachteten Beispiele die Durchführung des Thema unter- 
nehme, so werde ich gewiss mit der Seltenheit der in Rede stehenden Fälle beim Leser genügende Entschuldigung finden.

Frall A., 28 Jahre alt, von zartem, aber gesundem Bau, regelmässig menstruirt, von Jugend auf nervös und ziemlich anämisch, ist seit dem 20. Jahre mit einem kräftigen, nach der Angabe des Hausarztes nur an geringem chronischen Kehlkopfkatarrh leidenden, sonst durchaus gesunden Mann verheirathet. Sie abortirte im ersten Jahre der Ehe, angeblich im vierten Monate der Schwangerschaft, gebar hierauf ungefähr nach Ablauf eines Jahres leicht und schnell ein reifes Mädchen, welches jetzt noch lebt und nach Aussage der Eltern und des Arztes etwas zart, aber sonst gesund ist. Die dritte und vierte Schwangerschaft (der Zeit nach ungefähr anderthalb Jahre auseinanderliegend) endeten mit der Geburt je eines ziemlich reifen, etwas macerirten Knaben, der seit wenigen Tagen abgestorben war. Vor beiden Geburten hatte die Frau bis in die letzten Tage der Schwangerschaft sich ganz wohl und kräftig gefühlt, und immer lebhafte Kindesbewegungen beobachtet. Plötzlich waren beide Male die ganz gleichen Erkrankungserscheinungen an den Tagen der zu erwartenden Geburt aufgetreten: Frösteln, abwechselnd mit Kälteund Hitzegefühl, leichtes Fieber, Appetitlosigkeit, allgemeine plötzliche Ermattung, Kopfschmerz, schwere müde Augen, Benommensein, Schwere und Kühle im Unterleibe, verbunden mit allmäligem Verschwinden der Kindesbewegungen. Beide Male erfolgte nach mehrtägiger Dauer dieses Zustandes die schnelle Geburt unter Abgang von sehr wenig Fruchtwasser. Beide Knaben waren gross, kräftig, wohlgebildet, schon etwas von Fäulnissblasen bedeckt. Pemphigus an Händen und Füssen fehlte. Sectionen wurden nicht gemacht. Die Nabelschnüre beider fielen durch bedeutendes Oedem in der Nähe der Insertion am Foetus auf; sie waren stark gelb gefärbt, derber und fester als gewöhnlich.

Kurz nach der Entbindung war die Frau beide Male von Schüttelfrösten befallen worden, denen zunächst Tage grosser Ermattung, später ein ganz normaler Wochenbettsverlauf nachfolgte.

Anfang Januar 1874 waren die letzten Menses dagewesen. Die Schwangerschaft (die fünfte) verlief normal; ungefähr am 7 . October 1874 erwartete die Frau ihre Entbindung. Um einem ähnlichen übelen Ausgang der Geburt vorzubeugen, erbat sich die Frau ungefähr in der Mitte der Schwangersehaft den Rath des Herrn Professor Credé, welcher gegen das habituelle Absterben am Ende der Schwangerschaft die Einleitung der Frühgeburt in Vorschlag brachte. Am 5. October nun, also zwei Tage vor dem nach genauer Berechnung zu erwartenden Geburtsanfang stellten sich ähnliche Gefühle der Frau wie früher ein, doch nicht in der gleichen Stärke. Leichtes Frösteln, allgemeine Unruhe und Ermattung, etwas verminderter Appetit, Ringe um die Augen - dabei die Kindesbewegungen unverändert. An den beiden nächsten Tagen Zustand in Gleichem.

Am 7. October wurde ich in Stellvertretung des abwesenden 
Herrn Professor Credé gebeten, eine Untersuchung vorzunehmen. Die etwas magere, blasse, entschieden anämische Frau machte einen im Uebrigen durchaus gesunden Eindruck und gab an, die Bewegungen der Frucht eben noch lebhaft zu fühlen. Sie klagte über allgemeine Schwäche des Körpers und geringeren Appetit, leichtes Frieren und Unruhe, ein Zustand, der vielleicht durch die Sorge vor einem wiederholt ungïnstigen Geburtsausgange noch gesteigert worden war.

Die äussere Untersuchung ergab einen stark ausgedehnten Uterus, wahrscheinlich mit viel Fruchtwasser. Der Rücken des Kindes nach links; ebenda etwas schwache, aber deutliche Herztöne (136 in der Minute); zwischen diesen und dem Nabel der Frau ungefähr handbreit über der linken Inguinalgegend sehr starkes Nabelschnurgeräusch.

Bei der inneren Untersuchung fand sich der äussere Muttermund geöffnet, fünfgroschengross, der innere etwas enger; die Blase schlaff herabhängend, darüber der leicht bewegliche Kopf.

In Anbetracht des subjectiven Befindens der Frau, der schwächeren Herztöne und des starken Nabelschnurgeräusches, das höchst wahrscheinlich mit einem drohenden Absterben der Frucht im $\mathrm{Zn}_{1-}$ sammenhange stand, wurde am 7. October Nachmittags 5 Uhr zur Einleitung der Geburt ein flexibler, starker Katheter eingeführt, der an der vorderen Gebärmutterwand nach vorn und rechts leicht und ohne die Blase zu verletzen, bis zur Hälfte vordrang. Abends 1/210 Uhr traten die ersten Wehen auf; bis dahin waren die Kindesbewegungen immer noch deutlich gewesen.

Am 8. October früh Herztöne links in gleichem Befunde. Die Wehen waren wieder schwächer. Ich schob deshalb vorsichtig den Katheter bis ziemlich an das Ende in den Uterus ein, worauf die Wehen im Laufe des Vormittages immer stärker wurden. Mittags $3 / 412$ Uhr erfolgte der Blasensprung mit Abfluss einer mässigen Menge von Fruchtwasser, und halb 1 Uhr mit einer kräftigen Wehe die sehr schnelle und leichte Geburt eines lebenden Knaben, dem gleichzeitig der bis dahin liegengebliebene Katheter, eine bedeutende Quantität Fruchtwasser und kurz darauf die Nachgeburt folgte.

Unmittelbar nach der Geburt kam ich hinzu und fand einen kräftigen, wohlgebildeten Knaben, welcher allerdings der Anregung zum Schreien bedurfte, und auch im Bad mit kalten Begiessungen es nur zu mässigem Schreien mit schwacher Stimme brachte. Auf der Lunge war hinten leichtes Rasseln hörbar. Die Katheterisation der Luftwege brachte keinen Schleim hervor. Nach Anwendung der Marshall-Hall'schen Methode trat eine kräftigere Stimme und ruhiges Athmen ein. Das Kind jedoch blieb auffallend theilnahmlos, nahm nur wenig zu sich, wurde am Ende des ersten Tages ikterisch, noch mehr am zweiten Tage, dabei apathisch, kühl und schlaff, und starb am Ende des zweiten Tages unter zunehmenden Rasselgeräuschen auf beiden Lungen. 
Die Mutter blieb diesmal im Wochenbette frei von den starken Schüttelfrösten, welche sie die beiden letzten Male ergriffen hatten, und fühlte sich wesentlich wohler und kräftiger als die letzten Male. In Uebrigen war der weitere Verlauf vollständig normal.

Bei der am nächsten Tage angestellten Section zeigte sich, dass das Kind $\left(49^{1} / 2 \mathrm{Cm}\right.$. lang und genau 3000 Gramm schwer) alle Zeichen der Reife trug und abgesehen von der stark ikterischen Färbung der ganzen Hant und der zugängigen Schleimbänte keine Spur von Hauterkrankungen darbot. Horizontalumfang des Kopfes $34 \mathrm{Cm}$., Kopfknochen fest und derb. Das Fettpolster der Haut gut entwickelt.

Der Rest der Nabelschnur, welche sehon vor der Abnabelung durch ihr starkes Oedem und ihre gelbliche Färbung besonders in der Gegend des Nabelringes auffiel, war wenig eingetrocknet, noch ziemlich hydropisch und dick.

Nach Eröffnung der Brusthöhle zeigt sich, dass die linke Lunge ganz zusammengefallen und nach hinten gesunken ist, während der vordere Rand der rechten Lunge das Brnstbein erreicht. Beide untere Lungenlappen in ihren untersten Theilen luftleer, derb, fest, gleichmåssig dunkelbraunroth, hyperämisch; der obere Lappen der linken Lunge mehr als der der rechten von ein paar ungefähr linsengrossen, atelektatischen, braumrothen, eingesunkenen Stellen durchsetzt. Das Gewebe der übrigen Theile lufthaltig, hellgrauroth, normal. Die grossen Bronchien enthalten wenig Schleim. Ihre Schleimbaut geröthet. Das Herzfleisch etwas blasser als gewöhnlich. Die Thymus von normaler Grösse und Structur, ohne Ablagerting von Eiterheerden. Die Milz um das Dreifache vergrössert, prallgespannt, zeigt auf einer glatten, gleichmässigen Sehnittfäche durchaus normales Gewebe. Ihre Kapsel nicht verdickt, dunkelblauroth. Die Leber von gewöhnlicher Grösse und der bei Neugeborenen eigenthümlichen, dunkelvioletten Farbe; etwas ödematös, ohne sonstige Abnormitäten; namentlich liess sich an den längs- oder querdurchgeschnittenen Lebergefässen nirgends eine Verdickung der Adventitia nachweisen. Die Gallenblase prall gespannt, aber nicht ïbermässig ausgedehnt, entleext eine geringe Menge schwarzgrüner Galle. Die übrigen Organe des Unterleibes, wie Nieren, Pankreas u. s. w. anämisch, sonst normal. Die Schleimhaut des Magens und Darmkanales zeigt weder. Injection noch Schwellung. In der Brust- und Bauchböhle keine Vermebrung der natürlichen Flüssigkeit; noch irgendwelche Blutungen der Serosae. Die Untersuchung der Epiphysen musste aus Rücksichten unterbleiben.

Die Untersuchung der Placenta und der Nabelschnur bald nach. der Geburt bot mehrere beachtenswerthe Momente dar. Die fötale Seite der normal grossen Nachgeburt $(16: 18 \mathrm{Cm}$.) war an den Rändern wie in der Mitte von mehreren kleinen, bis ungefähr bohnengrossen, weisslichen, derben Knoten bedeckt, die unter dem Chorion lagen, eine gleichmässige, glänzende Schnittfläche zeigten und nach der mikroskopischen Untersuchung als dem Chorion ansitzende Fibrin- 
knoten anzusehen sind. Makroskopisch gleichen sie durehaus den weisslichen Knoten, die häufig genug auf der fötalen Seite von Placenten normaler Früchte beobachtet werden. Das Gewebe der mikroskopisch untersuchten Nachgeburt selbst war ohne Abnormitäten.

Die noch frische Nabelschnur wurde von der Abnabelungsstelle bis zum Placentarende mit einem scharfen Rasirmesser in Absätzen von einem Centimeter Entfernung ziemlich durchgesehnitten, um das Caliber der Gefässe zu untersuchen. Dabei ergab sich, dass das Lumen derselben, wie die Gefässwände selbst, abgesehen von sehr geringen Unterschieden, im ganzen Verlaufe ziemlich die gleichen blieben; dagegen liess sich eirca $6 \mathrm{Cm}$. von der Placentarinsertionsstelle entfernt eine so deutliche einseitige Verdickung der Nabelvene beobachten, dass nicht nu das Messer einen etwas stärkeren Widerstand fand, sondern auch der Finger an der Stelle eine knorpelartige Verdickung fühlte. Dieselbe erstreckte sich ungefähr einen halben Centimeter lang nach dem Placentarende hin, und verengte das Venenlumen ziemlich ïber die Hälfte. Die Nabelarterien zeigten an dieser Stelle keine nennenswerthen Veränderungen; nur ist bemerkenswerth, dass ungefähr von hier an bis zur Insertion am Foetus die Nabelschnur ihre besondere Schwellung und Prallheit zeigte. Unter dem Mikroskop erschien an dieser Stelle der Venenwand die Muscularis und Adventitia stark verdickt, von derben Bindegewebssträngen durchzogen; die Intima dagegen kleidete als feiner Sanm die Innenwand aus, ohne an der Hypertrophie Antheil zu nehmen.

An der Hand dieser Sectionsbefunde war es allerdings möglich, den Eltern die Todesursache dieses Kindes anzugeben; aber es war, wie wir sehen werden, nicht leicht, die eigentliche anatomische Ursache auf deren Quelle zurückzuführen.

Nach Analogie zahlreicher, in der Literatur veröffentlichter Fälle musste der erste Gedanke der an Syphilis der Eltern sein. Eine eingehende Nachfrage aber hierüber ergab vom Vater die wiederholte ruhige und freimuithige Erklärung, welche besonders mit dem Zeugniss des Hausarztes genau übereinstimmte, dass weder von seiner Seite, noch von der der Frau diese Annahme begründet werden könne. Und da an der Wahrheit dieses Ausspruches, wie an der Wahrheitsliebe des Vaters zu zweifeln, in der That nicht der geringste Grund vorlag, da die Eltern nach Aussage und frïherer Untersuchung von Seiten des Arztes die vergangenen Jahre nie krank waren, und die Mutter nach dem erst- und zweitmaligen Absterben des Foetus sich immer wieder schnell erholt hatte, so musste der Grund mit Hinblick auf eine eventuelle, vom Vater gewünschte Therapie in ganz anderen Momenten zu suchen sein. 
Sehen wir daher von eventueller angeborener Syphilis ab, für welche die Section des Kindes auch nicht ein absolut sicheres Zeichen darbot, so liegen zwei wichtige pathologisch-anatomische Befunde vor, die meines Erachtens in einem unbedingten Zusammenhange stehen, und Veranlassung zum baldigen Tod der Frucht nach der Geburt gegeben haben, ich meine die Stenose der Nabelvene und die Entzündung der unteren Lungenlappen. Während der ganzen Schwangerschaft hat sich Mutter: and Kind vollkommen wohl gefïhlt; erst in den letzten Tagen vor der zu erwartenden Geburt erschienen die von früher wohlbekannten, nur diesmal schwächeren Symptome des Fruchtabsterbens, die Herztöne wurden schwächer und ausserordentlich starkes Nabelschnursausen hörbar. Was liegt für die Erklärung dieser letzteren Umstände näher als die beträchtliche Stenose der Nabelvene, deren Entstehung ohne jeden Zweifel erst in die letzten Tage der Schwangerschaft fallen kann? Sie zeigt das mechanische Hinderniss im Blutstrome der Placenta und der Nabelgefässe und verlegt offenbar in die Nabelarterien das lebhafte Sausen; sie erklärt zunächst die Blutstauungen und Extravasatknoten in der Placenta, das bedeutende Oedem der Nabelschnur, vielleicht auch die beträchtliche Vermehrung des Fruchtwassers. Sie erklärt ferner die Abnahme der kindlichen Ernährung, daher die schwächeren Herztöne trotz dichten Anliegens des Rückens an die seitliche Bauchwand. Als weitere Folge hiervon trat aber während der Geburt durch die Stauung in den Nabelarterien ein Zustand der Asphyxie ein, welcher, da das Kind mit schwachem Leben und Rasseln auf den Lungen geboren wurde, intrauterine oder intravaginale Athembewegungen ausgelöst hatte. Auch wem dieselben bei der verhältnissmässig schnellen Geburt nur geringe gewesen sind, so genügte doch schon der dadurch auch nur in geringer Menge respirirte Schleim, eine Lungenatelektase und Lungenentzündung herbeizuführen, welche nach zwei Tagen den Tod des Kindes zur Folge hatte.

Wenn wir sonach die Stenose der Nabelvene als das Primäre und die Lungenentzündung als die eigentliche Todesursache bezeichnen, so bleibt freilich noch ein völliges Dunkel über jene Erkrankung der Nabelvene und die Todesursachen der beiden letzten Früchte. Jedoch werden wir weiter unten durch Betrachtung ähnlicher Fälle aus der Literatur den verschiedenen Ursachen näher zu kommen suchen. 
Diese Krankengeschichte giebt Veranlassung zwei Fragen aufzustellen, deren Beantwortung für weitere derartige Beobachtungen die Cardinalpunkte bilden müssen, nämlich erstens, worauf beruht das habituelle Absterben des Kindes, speciell in diesem Falle die primäre Erkrankung der Nabelvene? und zweitens, ist es gerechtfertigt, wie speciell in diesem Falle, dem intrauterinen Tod mit der künstlichen Frühgeburt vorzubeugen, und welche Ansichten und Erfolge liegen von Seiten der Autoren betreffs der künstlichen Frühgeburt wegen habituellen Absterbens bis jetzt vor?

\section{I.}

Die Ursachen des habituellen Absterbens.

Die folgenden Zeilen werden darlegen, wie weit die Meinungen der Autoren über die Ursachen des habituellen Absterbens auseinander gehen, und wie wenige positive und allgemein gültige Erfahrungen der pathologischen Anatomie wir den Sectionsbefunden abgestorbener Früchte zu Grunde legen können.

Ich stelle die überaus treffenden Worte d'Outrepont's ${ }^{\mathbf{1}}$ ) voran, da sie die klare Definition des habituellen Absterbens enthalten und nicht bessere diesem Capitel an die Spitze gestellt werden können.

„Unter habituellem Absterben der Kinder ver steht man jene nicht seltenen Erscheinungen, bei welchen eine Frau in verschiedenen aufeinander folgenden Schwangerschaften in dem nämlichen Zeitpunkte derselben ohne irgend eine anerkannte äussere oder innere Veranlassung todte Kinder gebärt; gewöhnlich geht dem Tode der Frucht ein heftiger Frost voraus, und die sämmtlichen Früchte sehen aus wie solche, welche längere Zeit im Mutterleibe wie todt getragen wurden. Je dunkler die Ursachen dieses so unangenehmen Ereignisses sind, und je weniger daher ihm zu begegnen ist, desto mehr verdient diese Sache die Aufmerksamkeit der Beobachter.

Die Ursachen des habituellen Absterbens der Kinder können entweder in dem resp. Organismus, in der Gebärmutter, in der rungen.

1) Neve Zeitschrift für Geburtskunde VI: Beobachtungen und Erfah- 
Frucht, in der Nabelschnur, in den Eihäuten oder im Mutterkuchen gesucht werden. In de $\mathrm{r}$ individuellen $\mathrm{Sphäre} \mathrm{konnte}$ ich keine Ursache ausmitteln, da die von mir beobachteten Personen sich übrigens einer vollkom menen Gesundheit erfreuten, und sonst auch niemals an Unregelmässigkeiten der Sexualfunction gelitten hatten. Ebenso verhielt es sich mit der Gebärmutter; an den Häuten, an Nabelschnur, so auch am Fruchtwasser zeigte sich ebenfalls Nichts von der normalen Form und Beschaffenheit Abweichendes. $N u r$ in der Ausartung der Placenta konnte ich bis jetzt die Ursache des in Frage stehenden Ereignisses auffinden. Es waren die Früchte meistens dürftig genährt, ihr übles Aussehen konnte die Folge des Todes nicht sein, indem sie sobald nach dem Aufhören der Bewegungen und auch gleich nach dem Abgange der Wässer geboren wurden, sondern man kann der Vermuthung Raum geben, dass die Ernährung wegen der Krankheit der Placenta schlecht von statten geht; wohl auch mag die Kirrhonose eine Folge des abnormen Zustandes dieses Organes gewesen sein. Ueber die Ursachen der erwähnten Ausartung der Placenta herrscht das nämliche Dunkel wie über alle anderen Krankheiten derselben."

Auch Simpson ${ }^{1}$ ) hat über das habituelle Absterben des Foetus und die Todesursachen desselben reiche Erfahrungen gesammelt; er fand, dass am häufigsten die Bauchfellentzündung den intrauterinen oder den bald nach der Geburt stattfindenden Tod zu früh geborener Früchte herbeiführe. Die Ursache dieser foetalen Erkrankung verlegt er entweder in Traumen oder äussere Schäden anderer Art oder in Syphilis der Mutter. Er beobachtete die Erkrankung nicht allein beim ersten Kinde, sondern auch nach der Geburt mehrerer gesunder Kinder, vor Allem aber nach früheren Aborten und nach der Geburt mehrerer todter Kinder. Bei den Sectionen zeigte insbesondere die Bauchhöhle die unzweideutigsten Erscheinungen acuter oder chronischer Entzündungen; nur ist hierbei anticipando auf die höchst interessante, bisher nicht genügend hervorgehobene Thatsache aufmerksam zu machen, dass fast in allen Fällen der todtgeborenen Früchte mit foetaler Peritonitis das Bauchhöhlenexsudat insbeson-

1) a. The works of Sir J. Y. Simpson. Vol. I. Obst. p. 102.

b. London and Edinburgh Monthly Journal of Medical Science. Febr. 1845. p. 119.

c. Schmidt's Jahrb. 47, 64 . 
dere, wie das der Brusthöhle und das Oedem der allgemeinen Bedeckungen ein blutig seröses war (cf. Hydrops sanguinolentus Martin), während die Peritonitis der lebend geborenen und erst später gestorbenen Früchte sich nur in rein serösem oder flockigen, oder hier und da auch eitrigen Exsudat darstellte.

Die Haut der todten Friichte war meist stark macerirt und hydropisch. Was die Dauer der foetalen Peritonitis anlangt, so beobachtete Simpson, dass sie erst ganz kurz vor der Geburt in etlichen Fällen entstanden sein konnte, denn die betreffenden Kinder wären sehr kräftig und derb zur Welt gekommen. Andere Fälle sprechen je nach dem absoluten Aufhören der kindlichen Bewegungen dafür, dass der Tod 2-3 Tage oder noch viel länger vor der Geburt eingetreten war. Die Wirkung dieser fötalen Peritonitis auf das Leben des Kindes ging dahin, dass ungefähr in der Hälfte der Fälle die Kinder vor der Geburt abgestorben und in beinahe ebensoviel Fällen lebend geboren, aber bald darauf (2-48 Std.) gestorben waren. Und wenn nun Simpson von allen diesen Beobachtungen das Resultat heraushebt, so lautet es dahin, dass die Ursachen des intrauterinen Todes weniger in Krankheiten der Mutter oder deren Genitalien, als in den Erkrankungen des Foetus selbst oder dessen Anhängen zu suchen sind.

Daher findet er die zweite wichtige Ursache des habituellen Absterbens der Früchte in den Erkrankungen der Placenta, deren Charakter und Folgen in trefflichster Weise von ihm geschildert werden. Hier sind es die Congestion und Apoplexie, diè Entzündung (Hepatisation, Induration und Abscess) einzelner Stücke der Placenta wie ihrer ganzen Oberfläche, die Gangrän kleiner Theile, ferner das allgemeine Oedem und der Hydrops der Nachgeburt, der bisweilen mit Hydrops und Anasarka des Foetus und des ganzen Nabelstranges zusammen vorkommt, der aber nicht zu verwechseln ist mit der blassen und anämischen Placenta, die oft in den Fällen gefunden wird, in denen die Frucht an Peritonitis zu Grunde ging und hierauf noch im Uterus zurückgehalten wurde.

Es ist ferner die fettige Degeneration, die mehr als Entzündung zu betrachten sei, und endlich die Hypertrophie der Nachgeburt, welche sich bei Müttern finde, die eine Reihe todter Früchte zu früh geboren haben. Ich kann unmöglich auf die Einzelheiten dieser Erkrankungen ausführlicher eingehen; später werde ich zeigen, von welchem Standpunkte ihr Werth und ihre Bedeutung zu beurtheilen ist; nur so viel möge den Schlüssen 
Simpson's noch entnommen sein, dass er späterhin geneigt ist, die intrauterin entstandene Peritonitis habituell abgestorbener Früchte auf Syphil is eines der beiden Eltern, besonders der Mutter zurückführen, die Erkrankungen der Nachgeburt aber als selbstständige Erscheinungen aufzufassen, die ohne Zusammenhang mit der Syphilis in den letzten Wochen der Schwangerschaft auftreten, und den Tod des Kindes nach sich ziehen. ${ }^{1}$ )

In der ausführlichsten Weise geht Fuhrhans') mit ausgezeichneten Literaturangaben auf die verschiedenen Todesursachen der Frucht ein und theilt sie in solehe, die erstens von der Mutter, zweitens vom Vater, drittens vom $\mathrm{Ei}$ ausgehen, viertens in äussere Schädlichkeiten und fünftens in bisher noch unbekannte Ursachen. Der reiche Inhalt dieser Untersuchungen macht es bei der grossen Dunkelheit, welche über die Todesursachen schwebt, wünschenswerth, die interessanten, hier zusammengetragenen Erfahrungen näher zu beleuchten. Die Ursachen, welche von der Mutter ausgehen, sieht Fuhrhans einmal in den Wechselverhältnissen der Wärme (zu starker und zu geringer) des Foetus, zweitens in der ungleichen Zufuhr von Sauerstoff und drittens in den Hindernissen der fötalen Ernährung. Diese Eintheilung der mütterlichen Störungen umfasst alle möglichen und denkbaren pathologischen Erscheinungen des mütterlichen Organismus, die nach den bisherigen Erfahrungen den Tod der Frucht in frühen wie in späten Schwangerschaftsmonaten herbeigeführt habe.

Die vom Vater ausgehenden Ursachen beruhen hauptsächlich auf allgemeinen oder lokalen schwächenden Erkrankungen, vor Allem auf Syphilis, welche selbst bei vortrefflichster Gesundheit der Frau den Tod des Foetus herbeiführen können, obwohl gesunde Frauen auch bei Krankheit des Mannes ganz gesunde Kinder gebären können.

Unter den vom Ei selbst stammenden Ursachen hebt Fuhrhans besonders die bisher bekannten Erkrankungen der Eihäute hervor, die zu geringe oder zu bedeutende Menge von Fruchtwasser, ferner eine grosse Reihe von Erkrankungen der Placenta, aus deren dunkler Beschreibung wir die Hypertrophie und Atro-

1) 1. c. S. 140 .

2) De morte foetus justo graviditatis tempore nondum finito. Diss. inaug. Marburg 1831. 
phie, die Verfettung, die Apoplexie, die Entzündung, die Kalkablagerung und die Geschülste der Placenta zu entnehmen haben. Ex erwähnt ferner die bekannten Abnormitäten des Nabelstranges und macht besonders auf die Verengerungen der Gefässlumina und die dadurch gegebenen Störungen des Blutlaufes aufmerksam.

Die Ursachen der vierten Reihe bestehen hauptsächlich in Medikamenten oder Traumen oder schweren Körperverletzungen, die physikalisch oder mechanisch eine Trennung des. Eies von der Uteruswand zur Folge haben.

Weit mehr aber als alle diese müssen endlich die Gründe interessiren, welche erfahrungsgemäss am schlagendsten für das habituelle Absterben sprechen würden. Aber offen bekennt Fuhrhans, dass oft genug der Tod des Foetus eintritt, ohne dass dessen Ursache nur annähernd ermittelt werden kann. Hier sei es besonders angeborene od er vererbte $D$ is position der Frau, oder es sei eine innere Disharmonie zwischen den Uterinnerven und den mit der Gebärmutter zusammenhängenden Theilen, welche das weitere Leben des Kindes aufheben. Vor Allem legt er auch hier wiederum besonderen Nachdruck auf die Gesundheit des Vaters, dessen Erkrankung auch mit völliger Schonung der mütterlichen Gesundheit den intrauterinen Tod der Frucht bewirken könne.

So unsicher noch in ihren Resultaten diese Beobachtungen der früheren Zeit sind, so leuchtet doch aus den meisten schon das Streben hervor, die verschiedenen pathologischen Befunde auf e i ne Grundkrankheit zurückzuführen, und nur zu schlagend sind in vielen Fällen die Beweise für Syphilis der Eltern.

Die immer grössere Aufmerksamkeit der Neuzeit warf daher ein neues Licht in diese dunkelen Verhältnisse. Wie es aber so oft geschieht, dass ein neues Argument gleichsam mit Vorliebe gesucht und gefunden und angewendet wird, wo die Beweisführung nicht immer absolut sicher, so geschah es auch hier mit der Syphilis. Und so sprach es Porter ${ }^{1}$ ) als einer der Ersten auf das Entschiedenste aus, dass auch bei scheinbar ganz gesunden Eltern der wiederholte Tod der Früchte vor oder bald nach der Geburt nur auf Syphilis auf Grund eclatantester Beispiele bezogen werden könne.

1) Dublin Quat. Journ. 1857. Nr 46. S. 267. 
Nur wenige Jahre später bekannte sich Martin ${ }^{2}$ ) zu der gleichen Ansicht; denn bei einer Besprechung von 22 von ihm eingeleiteten Frühgeburten und einer Kritik der Indicationen zu dieser Operation, berührte er auch das habituelle Absterben der Früchte in den letzten Monaten der Schwangerschaft und sagte, dass er ,unter den Foetalkrankheiten, welche sich bei demselben Elternpaare constant wiederholen, und somit ein Absterben der Früchte in den späteren Monaten auf einander folgender Schwangerschaften herbeiführen, aus eigener, obschon vielfältiger Beobachtung nur die eine kenne, welche er den Hydrops sanguinolentus foetus genannt habe. ${ }^{2}$ ) Und diese Krankheit, bei welcher die Früchte eine mehr oder weniger beträchtliche Ansammlung von Flüssigkeit mit geschrumpften Blutkörperchen gemischt, sowohl in verschiedenen serösen Säcken, z. B. in der Schädelhöhle, der Brust- und Bauchhöhle, als auch in dem Unterhautzellgewebe, und fast constant in der Nabelschnursulze zeigen, bei welcher die Epidermis nicht selten in grösseren oder kleineren Blasen erhoben oder abgestossen erscheint, - diese Krankheit des Foetus habe er da, wo sie wiederholt den Tod oder das Sterben der Früchte (denn in seltenen Fällen geringer Lntwickelung der Krankheit lebten die Früchte unter der Geburt, athmeten wohl auch einige Male unvollkommen nach derselben) zur Folge hatte, und wo er den Vater examiniren konnte, stets nur bei vorausgegangener, sogenannter constitutioneller Syphilis der Eltern angetroffen."

An diese in der Berliner geburtshülflichen Gesellschaft vorgetragenen Erfahrungen knüpfte sich eine lebhafte Discussion, in welcher Kauffmann und Brandt Fälle mit zu Grunde liegender Syphilis, Abarbanell und Krieger dagegen Fälle mit ursächlicher chronischer Metritis, resp. in früherer Zeit überstandener Intermittens mittheilten. Hierzu bemerkt Martin, „dass ihm unter einer verhältnissmässig grossen Zahl von Beobachtungen wiederholt bei demselben Elternpaare frühzeitig todtgeborener Früchte kein Fall, den er genauer, auch durch Nachforschung bei dem Vater, habe verfolgen können, vorgekommen sei, in welchem nicht vorausgegangene syphilitische Affection bei beiden Eltern oder doch beim Vater stattgefunden hatte. Er beobach-

1) Mon. f. Geb. 19. 85. 1862.

2) cf. Geutebrück, Diss. inaug. de hydrope sanguinolento foetus, Jenae 1843. 
tete wiederholt, dass Eltern im Anfange ihrer Ehe gesunde Kinder zeugten, später aber, nachdem der Ehemann oder die Frau eine syphilitische Infection sich zugezogen, mehrere an der von ihm unter dem Namen Hydrops sanguinolentus beschriebenen Krankheit abgestorbene oder doch bald an Pemphigus u. s. -w. erkrankende Kinder zur Welt brachten. Umgekehrt sah er auch mehrere Male, dass dergleichen Elternpaare nach mehrfachem babituellen Absterben ihrer Kinder, sobald als sie eine antisyphilitische Cur durchgemacht, später lebende Kinder zeugten, sowie in einem Falle dieselbe Frau, welche in erster Ehe mit einem syphilitischen Manne und selbst angesteckt drei in der genannten Weise abgestorbene Kinder gebar, in zweiter Ehe mit einem gesunden Manne viele recht gesunde und kräftige Kinder zur Welt brachte. Dennoch behaupte er nicht, dass es keine weitere Ursache des habituellen Absterbens der Früchte im Mutterleibe gäbe, und wünsche sehr die Mitheilung genau beobachteter und insbesondere hinsichtlich der Todesart der Früchte festgestellter Fälle von habituellem Absterben der Früchte, bei welchen Syphilis der Eltern mit Sicherheit ausgeschlossen sei."

Die unter Martin's Leitung geschriebene Dissertation von Bonnekamp') schildert hauptsächlich die Befunde von Hydrops sanguinolentus der habituell abgestorbenen Kinder. Sie sind für unsere ferneren Betrachtungen von Interesse. Stellen wir zunächst voran, dass es sich hier um todtgeborene Kinder handelt, so hatten dieselben einen schlaffen Körper und macerirte, in Blasen abgehobene Haut, von schmutziger oder gelber Farbe, hauptsächlich an Händen und Füssen abgestossen. In den Blasen eine wässerige, mehr weniger durchscheinende oder gelbrothe Flüssigkeit. Häufig Ascites oder allgemeines Oedem; oft das subcutane Zellgewebe des Unterleibes der Sitz einer blutig serösen Infiltration. Die Placenta bald klein, weich, bald von Apoplexieen durchsetzt, bald anämisch. Die Körperhöhlen von blutig seröser Flüssigkeit erfüllt. Die grösseren Eingeweide anämisch; Lungen und Nieren meist normal; Leber bisweilen erblasst oder erweicht; (Milz?); in der Flüssigkeit selten plastische Bestandtheile, wie Fibrin; das Blutserum arm an plastischen Stoffen.

1) De morte foetus habituali. Diss. inaug. Berlin 1863. 
Mit fünf kurzen Krankengeschichten, in denen je eines der Eltern syphilitisch war, zeigt nun Bonnekamp, dass wie in diesen, so in den meisten derartigen Beobachtungen nur Syphilis elterlicher Seits die Grundkrankheit sein könne. Doch hält er es für Unrecht, diese Erklärung auf alle die Fälle anwenden zu wollen, in denen ein hydropisches Kind geboren werde. Dafür sprechen vor Allem jene von Bourgeois, Simpson, Hohl, Martin und vielen Anderen veröffentlichten Zwillingsgeburten, welche ein todtes, hydropisches und ein gesundes, lebendes Kind zur Welt brachten, das auch gesund am Leben erhalten wurde. Auch macht er auf die mit dem Hydrops sanguinolentus so auffällig übereinstimmenden Notizen d'Outrepont's aufmerksam und betont, dass der äussere elende Habitus der todten Früchte und besonders die Maceration keinesfalls etwa die Folge der Fäulniss sein könne; denn die Geburten solcher Kinder bätten häufig sehr bald nach dem Aufhören der Bewegungen und bei noch erhaltenem Fruchtwasser stattgefunden; ausserdem würde diese Annahme durch zwei Beobachtungen von Osiander ${ }^{1}$ ) und Riecke unterstützt, welche frühreife, aber lebende Kinder entwickelten, die am ganzen Körper ron grossen Blasen bedeckt waren.

Von den vielen anderen bekannten Fällen der Literatur mit habituellem Absterben, die freilich oft ungenügend nur berichtet sind, sei es schwer, der Ursache nahe zu kommen; doch liesse sich auch in diesen die Syphilis absolut nicht ausschliessen; denn auch das Fehlen aller Zeichen einer fötalen Erkran$\mathrm{kung}$ beweise noch keineswegs, wie ein Fall von Campbell darlege (Rosen u. s. w. S. 51.8) ${ }^{2}$ ), dass der Tod von der Syphilis nicht ausgegangen sei.

1) Göttinger gelehrte Anzeigen. 1810. Bd. I.

2) Rosen, Om Afkommet of Syphilitiske og om Genesen of den medfödte Syphilis; med em Inletining; om Begrebet Syphilis. Kjöbenhaven 1859. Reitzel 8 .

cf. Schmidt's Jahrb. 112. 354: „Ueberdies kann auch in Fällen, wo der Abortus durch den Tod der Frucht mit Wahrscheinlichkeit bedingt wurde, syphilitische Infection derselben Ursache des Todes gewesen sein. Dafür zeugt nur das Aussehen der Frucht, denn wenn sie auch nicht mit abgelöster Epidermis und im Zustande von Fäulniss ausgestossen wird, so sprechen doch Atrophie und Mangel an Entwickelung für eine syphilitische Diathese derselben. Fehlt auch diese Atrophie, so kann der Abort nicht durch constitutionelle Syphilis der Eltern veranlasst worden sein; in diesen Fällen ist namentlich ein Reizungszustand der Genitalien der Mutter ia 
Zwei Jahre später, 1865, veröffentlichte Döbner') die Erfahrungen der Scanzoni'schen Klinik über künstliche Frühgeburt, und es ist bemerkenswerth, dass er zwei Ursachen des habituellen Absterbens der Früchte kennt, nämlich: die Anaemie der Mutter und die Syphilis. „Die Fälle, wo weder bei der Mutter, noch was bis jetzt zu wenig berücksichtigt wurde, beim Vater eine Krankheit als mögliche Ursache des Absterbens der Kinder entdeckt werden kann, möchten nicht häufig sein. Meist sind es schwächliche, chlorotische oder anämische Frauen, und dass derartige Blutanomalien oft ungünstig auf die Frucht einwirken, ist bekannt.

Sehr oft wird Syphilis die Ursache sein. Wenn wir auch keine Exantheme, keine Drüseninfiltrationen wahrnehmen, so berechtigt dies doch noch nicht, die Syphilis als Ursache vollständig auszuschliessen, da es eine latente Form derselben giebt; noch weniger, wenn wir nicht im Stande sind, den Vater genau zu untersuchen. Es ist möglich und wahrscheinlich, dass ein syphilitisches Kind von einer gesunden Mutter geboren werden kann, wenn auch Sigmund dieser von mehreren Syphilidologen ausgesprochenen Ansicht mit dem Bemerken entgegentritt, dass eine Uebertragung der Syphilis per semen nicht existire. Nehmen wir aber Obiges an, so können wir uns auch nicht wundern, hier und da bei gesunden Frauen habituelles Absterben der Früchte zu beobachten."

$\mathrm{Zu}$ den ganz gleichen. Ursachen des habituellen Absterbens: nämlich der Anaemie der Schwangeren und deren constitutionell syphilitischen Erkrankung bekennt sich Scanzoni ${ }^{2}$ ) und legt den Hauptwerth auf den letzteren Zustand.

Endlich ist noch zu erwähnen der Ausspruch Spiegelberg's ${ }^{3}$ ), dass das habituelle Absterben der Frucht auf erblicher Syphilis beruhe. Diese Ansicht, welche auf der Naturforscherversammlung zu Innsbruck 1869 vorgetragen wurde, fand in der sich an den Vortrag knüpfenden Discussion mehrere Gegner, indem Daridsohn und Hegar meinten, dass sie habituelles Absterben sicher auch ohne nachweisbare Syphilis beobachtet, und

Folge von Affection des collum uteri als Ursache zu betrachten, worauf zuerst Baumès und Colli n aufmerksam gemacht haben."

1) Würzb. med. Zeitschr. VI. 37.

2) Lehrbuch der Geburtshülfe. Wien, Seidel u. Sohn. 1867. II. S. 16.

3) Monatsschrift für Geburtskunde 34. S. 376. 
Birnbaum, dass er es auch bei chronischer Entzündung der uterinen Schleimhaut gesehen hätte, nach deren erfolgreicher Behandlung der Tod nicht mehr aufgetreten sei.

In einer späteren Arbeit') lässt es Spiegelberg, vermuthlich mit Bezug auf diese gegentheiligen Beobachtungen, dahingestellt, dass es Fälle giebt, in welchen hereditäre Syphilis dem habituellen Fruchttod nicht zu Grunde liegt.

Diese Erfahrungen der Autoren lassen die Ursachen des habituellen Absterbens der Frïchte in vier Momenten erkennen, erstens in der elterlichen Syphilis, zweitens in der Anämie, drittens in chronischen Gebärmuttererkrankungen,

und viertens in einer ererbten Disposition und - wie es scheint - einer individuell erhöhten Reizbarkeit der Mutter.

Es wäre in der That ein überflüssiges Unternehmen, wollte ich mich erst eines Längeren verbreiten über die elterliche Syphilis, die oft einer Reihe von Kindern das Leben gekostet hat. Hier sind es nur zwei Punkte, die aus diesem wichtigen Kapitel hervorgehoben werden müssen, da sie mit dem Inhalte unseres Thema im innigsten Zusammenhange stehen, nämlich die $\mathrm{Be}-$ weiskraft einzelner, bisher anerkannter Sectionsbefunde, und zweitens die verschiedenen Zeitpunkte, in welchen in Folge von Syphilis der intrauterine Tod einzutreten pflegt.

Die schöne Arbeit von Hecker ${ }^{2}$ ) über die Syphilis congenita innerer Organe, wie die neueren Untersuchungen von Oedman$\operatorname{son}^{3}$ ), Wegner ${ }^{4}$, , Fränkel ${ }^{5}$, Winckel ${ }^{6}$ ), Birch-Hirsch$f^{\prime} l d^{7}$ ) u. s. w. (abgesehen von den früheren Untersuchungen

1) Ueber den Werth der künstlichen Frühgeburt. Dieses Archiv I. S. 11.

2) Monatsschrift für Geburtskunde 33, S. 23.

3) Syphil. Casuistik. Nord. med. Arch. I, 4. S. 73. - Cf. Dies. Archiv I. S. 523 :

4) Virchow's Archiv 50, S. 305.

5) Ueber Placentarsyphilis. Dieses Archiv V, S. 1.

6) Berichte und Studien aus dem Königl. Sächs. Entbindungsinstitute zu Dresden. Leipzig 1874.

7) Beiträge zur pathologischen Anatomie der hereditären Syphilis Neugeborener, mit besonderer Berücksichtigung einer Veränderung der Bauchspeicheldrüse. Archiv für Heilkunde. 1875. 2. Heft. 
Depaul's, Simpson's, Virchow's, von Bärensprung's ') u. s. w.) haben gezeigt, in wie klarer Weise sich die angeborene Syphilis entweder in den äusseren und inneren Organen, Haut, Lungen, Thymus, Leber, Milz, Pankreas, serösen Höhlen, Knochen, oder in der Placenta oder in den Gefässen des Nabelstranges documentirt.

Obwohl diese Untersuchungen, besonders über die letzteren Organe, noch lange nicht abgeschlossen sind, so sind durch sie doch so bestimmte pathologisch-anatomische Thatsachen aufgestellt worden, dass im gegebenen Falle bei nachweisbarer oder nicht nachweisbarer elterlicher Erkrankung es oft nicht schwer fallen wird, den wahren Grund des habituellen Absterbens anzugeben. Jene Untersuchungen haben aber auch andererseits zur Genüge gelehrt, dass wir nicht selten in allen jenen Organen die prägnanten Symptome der Lues vermissen, während die zu Grunde liegende Syphilis der Eltern mit Sicherheit entweder bekannt oder nicht ausschliessbar ist. Es fragt sich daher, ob es ausser jenen Symptomen der äusseren und inneren Organe, abgesehen von der Atrophie und schlechten Ernährung, nicht noch Allgemeinerscheinungen des Foetus giebt, aus denen wir mit Gewissheit seine Infection annehmen können.

Martin glaubt zwar von jenem Symptomencomplexe, den er Hydrops sanguinolentus genannt hat, dass er meistens die Folge von syphilitischer Infection sei, und legt dieser Symptomengruppe einen entscheidenden Werth besonders für die Syphilis des Vaters bei. Aber ich möchte darauf hinweisen, dass dieser Hydrops nichts Specifisches ist; denn er findet sich in der oben geschilderten ausgesprochenen Weise nur bei todten, gleichviel ob syphilitischen oder nicht syphilitischen Früchten, und findet sich nicht bei solchen syphilitischen Frühgeburten, die nur wenige Stunden gelebt haben, bei denen er doch anch nach der Geburt zu finden sein sollte. Wo bleibt dann das Characteristicum des Hydrops sanguinolentus?

In seinem oben citirten Werke bringt Simpson in dem Kapitel über fötale Peritonitis, in der er eine Ursache des habituellen Absterbens sieht, eine Reihe höchst instructiver Krankengeschichten, aus denen hervorgeht, dass von zehn zu früh und todtfaul geborenen Früchten sieben serös blutiges Fxsudat in den verschiedenen Körperhöhlen hatten, während von den fünf

1) Die hereditäre Syphilis. Berlin 1864. 
lebend geborenen, aber sehr bald post partum gestorbenen Kindern auch nicht eines diesen sanguinolenten Hydrops, wohl aber serös-eitrige Peritonitis aufzuweisen hatte. Mahnt diese einfache Thatsache nicht daran, dass jener blutige Hydrops mit dem intrauterinen Tod in innigster Verbindung steht?

Ferner belegt Hecker ${ }^{1}$ ) seine Beobachtungen mit 17 Fällen; 15 von diesen Früchten wurden lebend geboren, und 10 derselben gingen sehr bald post partum zu Grunde. Bei allen sind genaue Sectionen gemacht worden, und nur bei drei der letzteren fanden sich die Zeichen frischer oder alter Peritonitis, während bei keinem, das nur wenige Minuten lebte, irgend eine Spur von Hydrops sanguinolentus gefunden worden ist.

Endlich hat Winckel in zwei Tabellen 23 durch Torsionen der Nabelschnur oder Stenose der Nabelvene abgestorbene, macerirte Früchte zușammengestellt. Zwanzig dieser Fälle sind genaue Sectionsangaben beigefïgt, und wir finden bei 16 von diesen ausdrücklich angegeben, dass die Körperhöhlen, besonders die Pleura und das Peritoneum, reichliches blutig-seröses Exsudat enthielten. Und da unter diesen Früchten syphilitische und nicht syphilitische sich befinden, so geht auch hieraus wieder hervor, dass der Hydrops sanguinolentus nicht eine fötale Erkrankung bedeutet, die sich speciell bei den Kindern syphilitischer Eltern vorfinde. Da die Frühgeburten der Letzteren in vielen Fällen, z. B. in wiederholten Schwangerschaften macerirte und todte Früchte sind, die erst mehrere Tage nach dem Absterben geboren werden, so nimmt es nicht Wunder, dass solche Kinder die Metamorphosen des Todes schneller oder langsamer eingehen und mit den hinlänglich bekannten Zeichen des todtfaulen $\mathrm{Zu}$ standes geboren werden.

Dass aus diesem daher nicht auf die Grundursache geschlossen werden kann, liegt auf der Hand; dass aber eine Reihe hintereinander geborener todtfauler Früchte mit Recht die Aufmerksamkeit auf elterliche Syphilis lenkt, ist eine Thatsache, die mit jenem pathologisch-anatomischen Befunde in gar keinem Zusammenhange steht. Es kann daher jener Hydrops sanguinolentus Martin als ein, nicht einmal constantes Symptom des intrauterinen Todes, wohl aber kaum als eine eigenthümliche fötale Erkrankung angesehen werden.

1) $1 . \mathrm{c}$. 
Wie verhält es sich nun mit den von d'Outrepont und Simpson als Ursachen des habituellen Absterbens angegebenen Momenten, der fötalen Peritonitis und den verschiedenen Erkrankungen der Placenta? Simpson selbst kommt im Resumé seiner Abhandlung zu der Vermuthung, dass die fötale Peritonitis mit serös-fibrinösem und serös-eitrigem Exsudate, oder als abgelaufener Process ihre Begründung in elterlicher Lues findet, und spätere Nachuntersucher haben diese Annahme bestätigt und diese Bauchfellentzündung mit der bekannten weissen Pneumonie (Weber) oder dem Pemphigus, oder den Abscessen der Thymus, den Syphilomen der Leber, den Verhärtungen des Pankreas u. s. w. auf eine Stufe gestellt. Das gleiche Schicksal hat nun auch die Placentarerkrankungen d'Outrepont's und Simpson's getroffen, in denen diese Autoren Krankheiten sui generis mit nachfolgendem Fruchttode erkannten. Die Arbeit Fränkel's über Placentarsyphilis hat sich auf das Eingehendste hierüber verbreitet und die Ueberzeugung drängt sich immer mehr auf, dass bestimmte Placentakrankheiten bei habituell abgestorbenen Früchten ebenfalls nur der Ausdruck einer gemeinsamen Ursache, der elterlichen Lues sind. Hieran reihen sich unter demselben Gesichtspunkte die Ansichten von Oedmanson und Winckel, welche die Gefässerkrankungen des Nabelstranges (Atheromatose, Verfettung, Verkalkung der Arterienintima, Stenoseu der Nabelvene), die sich bei frühreifen todten Früchten vorfanden, ebenfalls durch jene elterliche Erkrankung herbeigeführt sehen.

Es unterliegt keinem Zweifel, dass mit diesen Untersuchungen ein wesentlicher Fortschritt auf dem dunkelen Gebiete gemacht ist. Legt man aber, wie es nothwendig ist, den Maassstab an diese Resultate, so muss man offen bekennen, dass diese Untersuchungen vorläufig ein noch viel zu geringes Material umfassen, und dass wir viel weiter bereits in der Deutung der Pathologie der Placenta und der Nabelgefässe sein würden, wenn die Lehrbücher genaueste mikroskopische Untersuchungen jener Organe im ganz normalen Zustande enthielten, wie sie für die Beurtheilung einer pathologischen Erscheinung unbedingt nothwendig sind. Haben wir doch noch keine feststehende, normale mikroskopische Anatomie der Placenta oder des Nabelstranges und seiner Gefässe, geschweige denn ein Bild der Varietäten eines ganz normalen Fruchtkuchens, die sich ja häufig genug bei normalen Geburten beobachten lassen. Wir besitzen ferner, 
worauf auch Winckel aufmerksam gemacht hat, noch nicht erschöpfende Untersuchungen über die Caliberschwankungen der Nabelgefässe ganz gesunder Foetus und machen doch schon Schlüsse aus grösseren oder geringeren Abweichungen, ohne zu wissen, wie weit die Norm ihre Grenzen zieht, welchen Antheil z. B. bei den Gefässentartungen des Nabelstranges die normale Involution am Ende der Schwangerschaft hat.

Hier stehen wir vor einem Kapitel, das noch einer gründlichen Bearbeitung bedarf. Der Beurtheilung des scheinbar Pathologischen ist hier so lange der weiteste Spielraum gelassen, als bis eine wirkliche Grundlage durch die normale Anatomiegegeben ist. Und diese Grundlage würde einem so unbekannten Gebiete gegenüber, wie es das habituelle Absterben ist, ohneZweifel von der grössten Bedeutung sein.

Aus dem Kapitel der elterlichen Syphilis interessirt aber hier noch die andere Frage, zu welcher Schwangerschaftszeit der intrauterine Tod in Folge ron Syphilis einzutreten pflegt.

Hierüber geben die Autoren ziemlich übereinstimmend genügenden Aufschluss. Was zunächst die vorwiegende Erkrankung. der Mutter anlangt, so sagt $\left.M \ddot{u} l l e r^{1}\right)$, „Es ist gewiss, dass eine Frau, welche bei der Conception bereits syphilitisch ist und während der Schwangerschaft Erscheinungen einer vorgerückten Syphilis darbietet, diese Krankheit auf die Frucht übertragen wird, indem sie entweder frühzeitig abortirt oder späterhin (im 7. oder 8. Monate) ein todtfaules oder jedenfalls nur ein paar Tage lebendes syphilitisches Kind zur Welt bringt.

Ist aber die Mutter mit den der späteren Periode der Syphilis eigenen, schweren, tardiven Affectionen behaftet, so wird sie kaum mehr concipiren oder es wechseln dann Frühgeburten mit Todt geburten."

Und betreffs des Vaters äussert sich Schröder ${ }^{2}$ ): „Werden durch den fruchtbaren Coitus Mutter und Kind inficirt, so erfolgt in der Regel der vorzeitige Tod des Kindes und Abortus. Bleibt das Kind am Leben, so wird es regelmässig frühzeitig ge-

1) Compendium der Geschichte, Pathologie und Therapie der venerischeo Krankheiten. Erlangen 1869, Enke.

2) Lehrburch der Geburtshülfe. 4. Aufl. S. 345 . 
boren, ist schlecht entwickelt und stirbt meistens sehr bald nach der Geburt.“

In solchen Fällen nun, wo wir es mit deutlicher und noch bestehender Erkrankung der Eltern zu thun haben, hat es natürlich keine Schwierigkeiten, die Ursachen des habituellen Absterbens zu erkennen. Viel grössere praktische Wichtigkeit haben aber jene, nicht gerade seltenen Fälle, wo bei einem der Eltern die Syphilis latent ist, wo keine Spur einer bestehenden Erkrankung sich nachweisen lässt, wo die Eltern vollständig gesund erscheinen und daher für das wiederholte Absterben ihrer Kinder scheinbar kein Grund aufzufinden ist. Hier aber unterscheiden sich in ihren Folgen die Latenz des Vaters und Mutters ziemlich von einander. ,Ist die Syphilis der Mutter zur Zeit der Conception latent, so werden meist anscheinend normale Kinder geboren, die erst später erkranken. Ist aber Syphilis des Vaters zur Zeit der Conception latent; so erfolgt in der Regel der vorzeitige Tod des Kindes und Abortus; oder wenn das Kind am Leben bleibt, so wird es regelmässig frühzeitig geboren, ist schlecht entwickelt und stirbt meistens sehr bald nach der Geburt, und die Mutter kann wahrscheinlich durch die Frucht gleichfalls inficirt werden." "1)

In ähnlichem Sinne fasst $\mathrm{Voge}^{2}$ ) seine Erfahrungen in die Worte zusammen: „In der grossen Mehrzahl der Fälle stammt die hereditäre Syphilis vom Vater, nicht von der Mutter.

Ist die Mutter secundär syphilitisch, so kommt die Schwangerschaft fast niemals zu ihrem normalen Ende, sondern es erfolgt Abortus oder mindestens Frühgeburt.

Wenn der Vater an secundärer Syphilis leidet, so kann die Mutter ganz intact bleiben und dennoch ein syphilitisches Kind gebären, ja es kann sich die Empfängniss und Geburt solcher Kinder sogar mehrmals repetiren, ohne dass die Mutter im Geringsten inficirt würde.“

Aus diesen bestimmten Șätzen, welche durch die schon oben citirten Fälle von Simpson, Bärensprung und Hecker unterstützt werden, tritt die Thatsache klar entgegen, dass, abgesehen von dem frühen abortiven Zugrundegehen des. Foetus in jenen Fällen, wo derselbe der vollen Einwirkung

1) Sçhröder, 1. c. - Hecker, l. c. - v. Bärensprung, 1. c.

2) Lehrbuch der Kinderkrankheiten. 4. Auf. S. 496. Erlangen 1869. Enke. 
der Krankheit unterliegt, die inficirte Frucht in den meisten Fällen zu früh (im 7., 8. und 9., selten im 10. Monate der Schwangerschaft) und zwar in vielen Fällen auch todtfaul geboren wird; und dass sie, wenn zu früh,. aber lebend geboren, meistens schnell nach der Geburt stirbt. Und was bei mehrmaligem in Folge von $\mathrm{Sy}-$ philis nach einander eintretenden Fruchttod speciell den Zeitpunkt der Schwangerschaft betrifft, in denen der Tod des Kindes. und die Geburt stattfand, so geht aus einer Durchsicht der zahlreichen von Bärensprung citirten Fälle mit ziemlicher Sicherheit und Uebereinstimmung hervor, dass die wiederholten Frühgeburten weit häufiger auf versch ie d e n e Schwangerschaftsmonate (z. B. das eine Mal den 8, dann den 7., dann den 10., dann wieder den 3. Monat und umgekehrt) und wohl in den seltensten Fällen auf den gleichen Monat oder gar die gleiche Schwangerschaftswoche fallen.

Zollen wir diesen Thatsachen die vollste Beachtung, so kann, wie wir später sehen werden, kein Zweifel darüber auftreten, welche Stellung dieselben der künstlichen Frühgeburt gegenüber einzunehmen haben.

In der nachstehenden Tabelle I. sind eine Reihe von Fällen aus der Literatur zusammengestellt, in denen $\mathrm{zu}$ wiederholten Malen die Früchte intrauterin abgestorben sind. Prüft man nun diese Fälle betreffs ihrer ursächlichen Momente, so kann es nach den vorausgegangenen Erörterungen, auch ohne in zu vielen Dingen sofort Syphilis sehen zu wollen, nicht schwer sein, in einzelnen die zu Grunde liegende Lues zu erkennen.

Indem ich zuerst die fünf Fälle Bonnekamp's (Tabelle I. 12-16) hervorhebe, da bei ihnen die congenitale Syphilis sicher gestellt ist, so ergiebt die Tabelle, dass hier die meisten Früchte (bei einer Frau sechs nach einander) im 7. oder 8. Monate macerirt und todtfaul geboren wurden, während zwei lebend geborene sehr bald nach der Geburt gestorben sind. Hieran schliesst sich die interessante Beobachtung Hayes's (Tabelle I. Nr. 18), nach welcher eine angeblich nie syphilitisch erkrankte Frau nach der Geburt dreier gesunder Kinder ihre 4.-16. Schwangerschaft immer im 7. (das erste Mal im 8.) Monate mit der Geburt todter Kinder beendete. Nur die 17. Schwangerschaft endete zwar rechtzeitig, aber doch mit der Geburt einer schwachen, macerirten Frucht. Die Placenta derselben war klein, weissgelb, anämisch, 
und die künstliahe Frühgeburt.

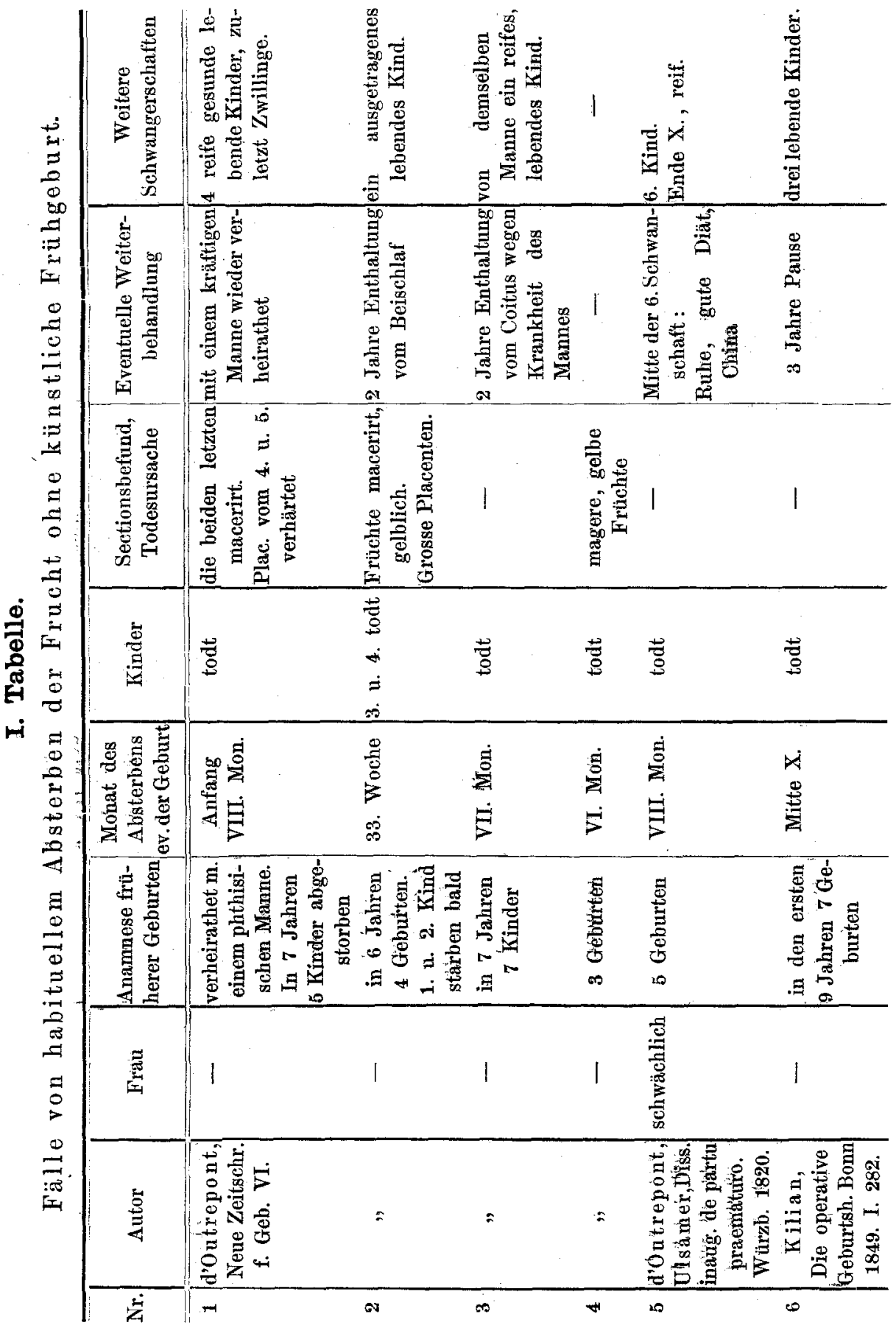




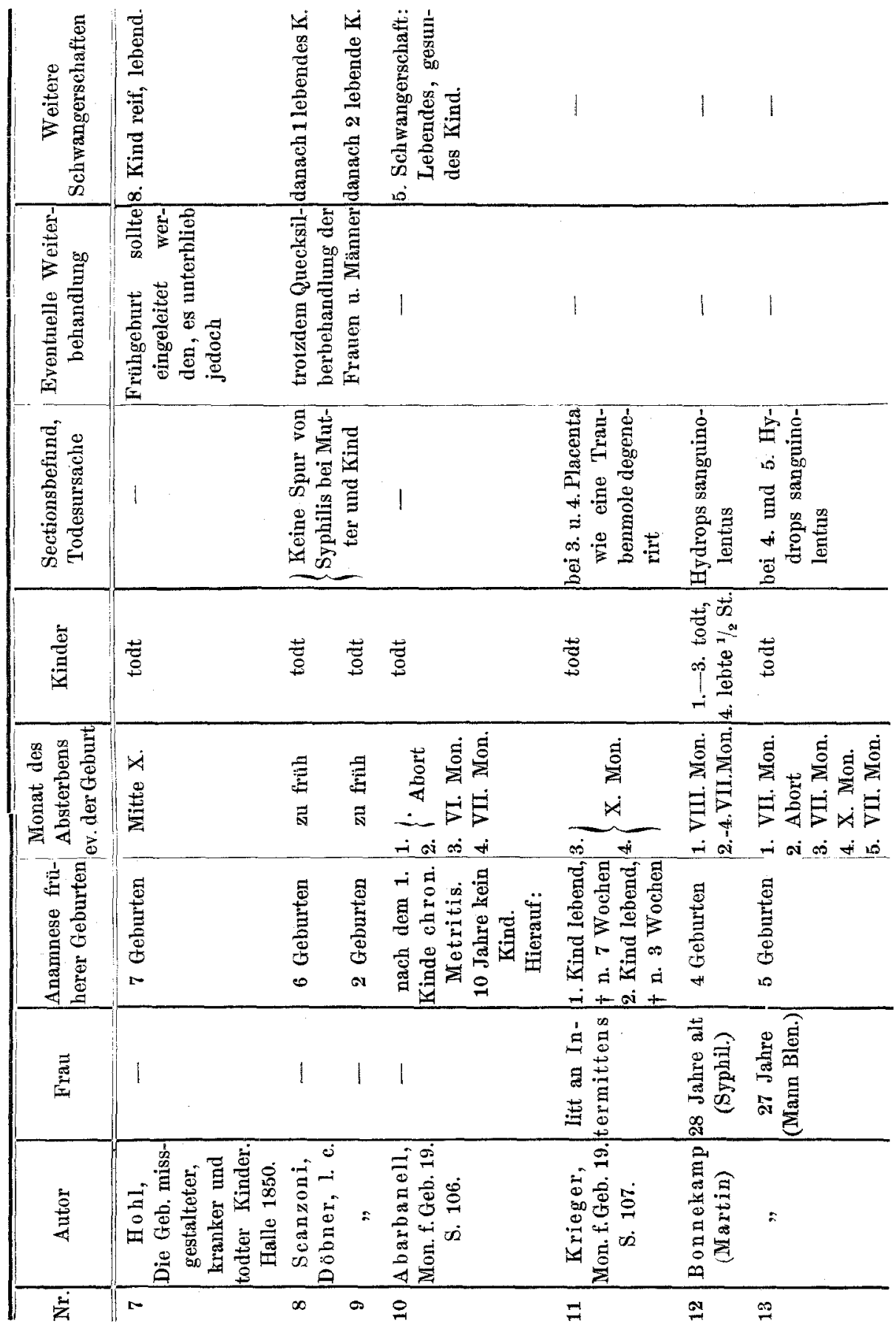


und die künstliche Frühgeburt.

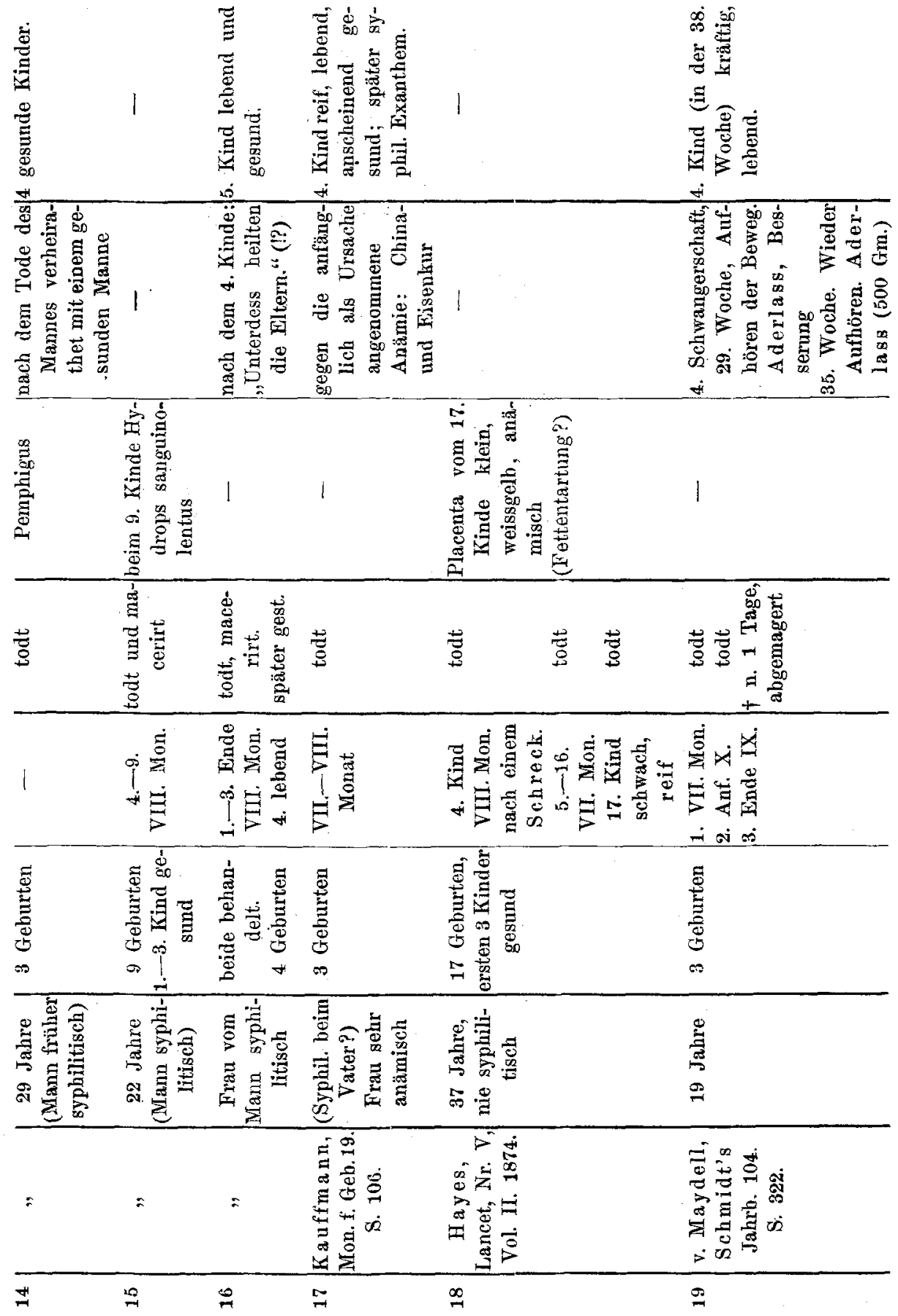


und zeigte starke Fettentartung, welche Hayes und Barnes von den häufigen Fehlgeburten und Blutungen während der letzten Schwangerschaft, aber nicht etwa von einer Placentitis herleiteten. Nach den Untersuchungen Fränkel's hat freilich die Deutung dieses Befundes als syphilitische Veränderung ihre Berechtigung; doch möchte ich hier vorläufig darauf hinweisen, dass allerdings dieser Fall auch eine andere Deutung zulässt.

Die beiden Fälle von Scanzoni hingegen (8 und 9) sprechen entschieden für eine luetische Infection. Von den beiden erstern Frauen hatte die eine sechs, die andere zwei todte Früchte zu früh geboren. Weder an Mutter, noch an Kind war eine Spur von Syphilis zu erkennen; und trotzdem liess Scanzoni die beiderseitigen Eltern eine antisyphilitische Cur durchmachen, worauf die erstere ein, die andere zwei lebende Kinder gebar. In diesen Fällen lässt sich allerdings nur ex juvantibus auf die wahre Ursache schliessen, obwohl es immerhin auffällig bleibt, dass auch die Kinder kein einziges Zeichen der angeborenen Lues dargeboten haben.

Auch in den Fällen d'Outrepont's (Nr. 1,2 u. 4) scheint es ungezwungen, auf Infection der Eltern zurückzugreifen. Im ersten Falle, in dem die kräftige, gesunde Frau mit einem phthisischen (?) Manne verheirathet war, wurden die fünf ersten Kinder innerhalb sieben Jahre im achten Monate todtgeboren, die beiden letzten macerirt mit verhärteten Placenten. Nach dem Tode dieses kranken Mannes erschienen von einem zweiten kräftigen Manne sechs gesunde Kinder, darunter zuletzt noch Zwillinge, eine Umänderung, die nach der Geburt syphilitischer Früchte nicht selten (wie im 3. Falle Bonnekamp's (Nr. 14)) vorgekommen ist. In der zweiten Beobachtung d'Outrepont's gebar eine Frau innerhalb sechs Jahren vier Mal nach ihrer Rechnung in der 33. Woche. Sie war sich keiner Veranlassung der Frühgeburt bewusst, ausser allenfalls des zu oft getriebenen Beischlafes. Die zwei ersten Kinder kamen lebend auf die Welt, waren aber sehr dürftig genährt und starben bald; die dritte, todte Frucht war sehr mager und hatte ein gelbliches Aussehen; ihre Placenta, ungewöhnlich dick, wog mit der Nabelschnur und den Eihäuten ca. 600 Gramm (cf. Fränkel). Bei der vierten Geburt war die Frucht auch todt, schlecht genährt; der Mutterkuchen ebenfalls sehr dick und hatte einen Umfang von $60 \mathrm{Cm}$. mit einem Gewicht von 750 Gramm. 
Im vierten Falle endeten bei einer Bürgersfrau, die sich eines glücklichen Looses erfreute, die drei ersten Schwangerschaften schon im sechsten Monate mit todten, mageren, gelblichen Früchten, von welchen die Placenta des letzteren hypertrophisch und äusserst hart war.

Es liessen sich hier noch eine grosse Reihe von Beispielen anführen; doch verweise ich besser zu diesem Zwecke auf die Beobachtungen von Bärensprung's, welche eine Fülle der hier erwähnten Thatsachen enthalten.

Ausser der elterlichen Syphilis lernten wir als zweite $U$ r sache des habituellen Absterbens der Früchte die Anämie der Schwangeren kennen, deren Vertreter Scanzoni und Döbner waren.

Nachdem sich der Erstere im 2. Bande seiner Geburtshülfe S. 3 u. folg. ausführlich über die Blutbeschaffenheit der Schwangeren und deren ïblen Einfluss auf die ganze Schwangerschaft ausgesprochen hat, fügt er hinzu: „Es kann nicht befremden, dass der blutarme Zustand der Mutter einen nachtheiligen Einfluss auf das Leben des Foetus ausübt, und bleibt es späteren Beobachtungen vorbehalten, nachzuweisen, ob nicht eine beträchtliche Anzahl der Fälle von sogenanntem habituellen Absterben des Foetus in diesen Verhältnissen ihren Grund hat. So könnten wir zwei in der letzten Zeit beobachtete Fälle anführen, in welchen der in mehreren aufeinanderfolgenden Schwangerschaften intrauterin eingetretene Tod der Früchte in der Anämie der Mutter eine ganz ungezwungene Erklärung fand.“

Und auf Seite 70: „Das Absterben der Frucht kann bedingt werden durch chronische und acute Anämieen: Wir exinnern nur an die Häufigkeit von Aborten bei Chlorosen, bei Individuen, welche in Folge äusserer Verletzungen bedeutende Blutverluste erlitten haben, bei solchen, welche wegen Armuth, Hungersnoth $u$. s. w. eine nur ungenügende Menge von Nahrungsmitteln zu sich nehmen. So will Hoffmann. während der Hungersnoth zu Leyden ungemein viele Aborte beobachtet haben, und denselben Einfluss schreibt Naegele der Missernte vom Jahre 1816 zu."

Dieser Hinweis Scanzoni's auf die Anämie der Mutter erfordert um so mehr die grösste Beachtung, als Scanzoni selbst nicht einseitig in der Beurtheilung der Motive des intrauterinen Todes vorgegangen ist und vor der Anämie vor Allem die constitutionelle Syphilis betont hat. 
Scanzoni's Vermuthungen haben nun in der jüngsten Zeit durch Gusserow ${ }^{1}$ ) eine glänzende Bestätigung erfahren. Denn aus dessen Schilderung der hochgradigsten Anämie bei fünf Schwangeren, welche gegen den 8 . Monat todte Früchte zur Welt brachten und bald darauf starben, geht wohl ohne Zweifel hervor, dass diese hohe Anämie ,eine der Schwangerschaft in specie eigenthümliche Erkrankung" ist, welche mit dem weiteren Fortschreiten der Gravidität sich rapid steigerte, die Frucht im Mutterleibe absterben liess und mit dem Tode endete, nachdem „die Geburt auf der Höhe der Erkrankung gleichsam als Vorläufer des Todes" eingetreten war.

Fragt man nun bei diesem scharfen Krankheitsbilde nach den Todesursachen der Kinder, so drängt sich obne Weiteres der Gedanke auf, dass die Frucht von einer so hochgradig blutarmen Mutter unmöglich das genügende Ernährungsmaterial empfangen haben kann und in Folge dessen atrophisch zu Grunde gegangen ist.

Die Mütter in diesen fünf Fällen waren jung, im Alter von 24-36 Jahren. Vier von ihnen waren Mehrgebärende; sie hatten die Kinder sehr rasch nach einander geboren.

Die erste in neun Jahren 6 Kinder, die zweite in zwölf Jahren 7 Kinder, die dritte (29 Jahre alt) in ? Jahren 5 Kinder, die vierte in zehn Jahren 9 (!) Kinder.

Wenn nun auch diese Mütter, ausser der dritten, in den früheren Schwangerschaften immer gesund gewesen waren und gesunde Kinder geboren hatten, so legt doch ihre letzte, für Mutter und Kind verhängnissvolle Schwangerschaft die Frage nahe, ob nicht auch schon gering ere Grade von Anämie bei schwangeren Frauen einmal und wiederholt auftreten können, die nicht so schwer sind, um Kind und gleichzeitig Mutter dahinzuraffen, wohl aber doch so bedeutend sind und werden können, um in den späteren Monaten, wo das Kind mit der schnelleren Zunahme auch immer mehr Ernährungsmaterial braucht, die nothwendige Nahrung nicht mehr zu produciren und somit die Frucht absterben zu lassen.

Diese Erwägungen folgern sich ungezwungen aus jenen interessanten Beobachtungen Gusserow's, und die beiden obigen Fälle Scanzoni's mögen als illustrirende Beispiele herangezogen

1) Dieses Archiv II. S 218. 
sein. In dem letzteren ') suchte eine Frau, welche schon vier Mal im 7. Schwangerschaftsmonate todte Früchte geboren hatte, im vierten Monate ihrer 5. Schwangerschaft wegen des habituellen Absterbens der Kinder in der Anstalt Hülfe. Die Untersuchung ergab keine Spur von Syphilis. Das Aussehen der Kranken deutete auf keine chlorotisch-anämische Blutmischung. Die von Förster vorgenommene mikroskopische Untersuchung des Blutes ergab jedoch eine auffallend grosse Anzahl weisser Blutzellen. Neben guter Kost gab man derselben Martialia. Doch zu Anfang des 8. Schwangerschaftsmonates erfolgte wiederholt die Geburt eines macerirten Kindes, bei dessen Section man viel Flüssigkeit im Gehirne, Herzbeutel, Brust- und Bauchböhle, sowie eine stark vergrösserte Milz und Blutarmuth aller Organe vorfand. In ihrer 6. Schwangerschaft kam dieselbe abermals in die Anstalt, wo in der 28. Schwangerschaftswoche die Frühgeburt eingeleitet wurde. In der 7. Schwangerschaft, die in der 37. Woche ebenfalls mit der Geburt eines macerirten Kindes endete, wurde von Eichwald jun. aus Petersburg eine genaue chemische Analyse des Blutes vorgenommen, die eine bedeutende Abweichung der Procentzahlen des untersuchten Blutes von der von Scherer und Otto für das normale Blut aufgestellten Zahlen ergab.

Ich selbst vermag nur den einen, dieser Abhandlung zu Grunde gelegten Fall hier anzuführen, indem die sehr anämische Frau schnell nach einander vier Kinder geboren und das dritte und vierte fast ganz ausgetragen hat, und zweifle nicht, dass ganz ähnliche Fälle von wiederholtem Absterben der Frucht einzig und allein in Folge von Anämie der Mutter auch von Anderen beobachtet worden sind.

Ehe aber diese Sätze, wenn sie auch schon auf den Namen der grössten Wahrscheislichkeit Anspruch machen können, sichere Gewissheit erlangen, sind genaue Beobachtungen in dieser Hinsicht noch abzuwarten, die jedoch noch mehr Punkte zu berücksichtigen haben, als es bisher geschehen ist. Hierher gehören genaue Angaben über die Gesundheitszustände der Eltern, besonders des Vaters, über die unbedingte Ausschliessung der elterlichen Lues; ferner über die pathologischen Befunde der abgestorbenen

1) P. Müller, Berichte über die geburtshülf liche Klinik zu Würzburg. Würzb. medic. Zeitschrift VI, S. 160. 
Früchte, über ihre Grössenverhältnisse, über den Eintritt des intrauterinen Todes und der Geburt, vor Allem aber über die Nachgeburten und die Gefässe des Nabelstranges, die bei zu Grunde liegender Anämie vielleicht ebenso wie bei vorliegender Lues bestimmte pathologische Erscheinungen darbieten können.

Wir sehen somit, dass auch hier wiederum ein Kapitel vorliegt, das überall Lücken und Unvollkommenheiten zeigt und darum noch die ausgedehntesten Untersuchungen verlangt.

Aus den weiteren Fällen der Literatur (Tab. I.) lassen sich hierfür zwei den Scauzoni'schen ähnliche Beobachtungen heranziehen. Zunächst der schon oben erwähnte Fall von Hayes, in dem eine Frau innerhalb 16 Jahren 17 Mal geboren hat. Die drei ersten Kinder waren gesund; die 4 . Schwangerschaft endete in Folge eines Schreckes im achten Monate mit einem todten Kinde. Von nun kränkelte die Frau, welche mit Bestimmtheit keine Spuren der Lues darbot, fortwährend und trug in den folgenden $\mathrm{z}$ wölf Schwangerschaften die Früchte nur bis zum siebenten Monate.

In diesem Falle ist die rasche Aufeinanderfolge der Schwangerschaften ebenso frappant, wie in Gusserow's Fällen. Nun ist es allerdings hinlänglich bekannt, dass eine grosse Anzahl selbst zarter Frauen, unbeschadet ihrer eigenen und der kindlichen Gesundheit, schnell nach einander viele reife und gesunde Kinder gebären können. Auch Gusserow hat auf dieses Moment hingewiesen. Dass aber wirklich die Anämie oder die Chlorose je nach ihrer Intensität einen übelen Einfluss auf die Frucht ausüben und dieselbe auch nur ein bestimmtes Alter erreichen lassen kann, dafür scheint mir auch der folgende Gesichtspunkt noch zu sprechen.

Es ist ja bekannt genug (ich verweise nur auf die Worte Schröder's hierüber, Lehrb. d. Geburtsh. S. 420), dass anämische Frauen oft hintereinander, eben nur in Folge ihrer abnormen Blutbeschaffenheit, im 3. oder 4. Monate abortiren, und es ist andererseits eine oft genug zu erlebende Erfahrung, dass anämische Frauen zwar austragen, aber elende Kinder zur Welt bringen, die entweder bald eingehen oder ein klägliches Aussehen behalten.

Obwohl wir allerdings soweit in der Physiologie der Schwangerschaft, speciell der Ernährung des Kindes und der Wechsel- 
beziehung zwischen Mutter und Frucht noch nicht sind, um eine streng wissenschaftliche Entscheidung in jedem einzelnen Falle zu geben, so ist doch vorläufig jedenfalls die Annahme erlaubt, dass in den letzteren Fällen die schwangere Mutter weit mehr Nahrung für das Kind haben muss und auf längere Dauer an dasselbe abgeben kann, als in den ersteren. Warum sollen dann nicht auch die Fälle möglich sein, wo die Mutter diese Leistungsfähigkeit nur bis zur Hälfte der Schwangerschaft oder ziemlich bis an das normale Ende derselben besitzt? Und in der letzteren Hälfte, wo das Kind mit jeder Woche bei dem enorm fortschreitenden Wachsthume eine offenbar immer grössere Nahrungszufuhr braucht, diesen Anforderungen nicht mehr gerecht werden kann? Die natürliche Folge hiervon kann nur der intrauterine Tod der Frucht sein in Folge von Anämie; die Folge hiervon wieder die Frühgeburt, deren Eintritt nach dem erfolgten Tode verschiedenen Schwankungen unterliegen kann.

Auch der von d'Outrepont beobachtete und von Ulsame $\left.\mathbf{r}^{1}\right)$ mitgetheilte Fall darf wohl mit Recht hier angeführt werden (Tab. I. Nr. 5). Fünf Mal nach einander waren im achten Monate die Früchte einer sehr zarten und schwächlichen Frau abgestorben und ca. 14 Tage danach erst geboren worden. In der Mitte der 6. Schwangerschaft liess d'Outrepont durch strengste Ruhe, Schlaf und gute Ernährung die Frau kräftigen. Sie trug hierauf diese Schwangerschaft aus und gebar ein reifes Kind.

Es wäre ein voreiliger Schluss, dieses Mal die Frühgeburt allein durch die Kräftigung der Frau verhütet zu sehen; wenigstens hatte die Behandlung der Anämie im Falle Scanzoni's (s. oben) gar keinen Einfluss auf die noch eintretende Frühgeburt; ausserdem sind auch Fälle bekannt, wo auf mehrere todte Frühgeburten spontan reife Kinder gefolgt sind. Und doch lässt sich wohl soviel behaupten, dass die grösste Schonung und die körperliche Kräftigung der Frau einen wesentlichen Antheil an der Erhaltung des Kindes gehabt hat.

Ein Einwurf lässt sich allerdings gegen die gewiss nicht unbegründete Theorie der mütterlichen Anämie und speciell gegen die hierfür angeführten Beispiele (mit Ausnahme der von Gusserow) machen; ob nicht auch diesen, freilich nur kurz beschrie-

1) Diss. inaug. de partu praemat. . Würzb. 1820. 
benen Fällen von habituellem Absterben Lues der Eltern resp. des Vaters zu Grunde liegt. Mag man diesen Einwurf machen, so ist doch zu bemerken, dass es freilich nichts Leichteres giebt, als sofort Syphilis hinter dunklen pathologischen Verhältnissen zu vermuthen, und diese Krankheit auch ohne Weiteres solchen Fällen unterzuschieben, welche mit thatsächlich durch Lues complicirten Beobachtungen Aehnlichkeit haben. So schlagende Thatsachen, wie sie Gusserow erzählt hat, rechtfertigen gewiss die vorgetragenen Ansichten, und ich übergebe dieselben der Beurtheilung der Fachgenossen, mit eventuellen Erfahrungen zur Klärung dieser Fragen beizutragen.

An die Anämie der Mütter als ätiologisches Moment schliessen sich selbstredend mütterliche chronische Erkrankungen, welche direct mit einer Blutänderung verbunden sind. So ist ein interessanter Fall mit zu Grunde liegender Intermittens zu erwähnen, den Krieger ${ }^{1}$ ) berichtet hat. Eine Frau, die er lange Zeit an Milzanschwellung behandelte, und bei der, sowie bei ihrem Manne keine Spur syphilitischer Erkrankung je vorgekommen war, gebar im Jahre 1855 ein lebendes Kind, welches sieben Wochen alt an einer Zellgewebsentzündung des Halses starb; im Jahre 1856 abermals ein lebendes Kind, welches drei Wochen alt an Icterus und Lungenlähmung starb. Bei der folgenden Schwangerschaft 1858 erkrankte die Frau an wassersüchtiger Anschwellung der Schenkel und des Unterleibes mit grosser Athemnoth, gebar etwa vier Wochen zu früh ein scheintodtes Kind, welches zwar im Bade noch zuckte, indess nicht athmete; die Placenta war ähnlich einer Traubenmole degenerirt. Bei der nächsten Schwangerschaft 1860 litt sie wieder an erheblichen Oedemen und gebar drei Wochen zu früh ein todtes, wassersüchtiges Kind mit enormer Hypertrophie der Nieren. Die Placenta abermals zum Theil in eine Traubenmole verwandelt. Als Ursache kann Krieger nur eine in früherer Zeit überstandene Intermittens mit chronischer Milzanschwellung bezeichnen.

Wenn es in diesem Falle sicher gestellt ist, dass die Eltern frei von Syphilis waren, so würde der Grund für die Frühgeburten der beiden letzten todten Kinder auch nur in der veränderten Blutbeschaffenheit der Mutter zu finden sein, und ist es dann sehr bemerkenswerth, wovon in den obigen für Anämie sprechen-

1) Monatsschr. für Geb. 19, S. 107. (Tab. I, Nr. 11.) 
den Beispielen nichts erwähnt ist, dass in diesen beiden Fällen die Placenta myxomatös entartet erschien und das eine Mal anch das Kind eine intrauterin erworbene Erkrankung zeigte. Dass in diesem Falle die Placentaerkrankung das Primäre gewesen wäre, wird wohl kaum Jemand behaupten.

Es ist zu beklagen, dass die Pathologie der Schwangerschaft bisher so stiefmütterlich behandelt geblieben ist und keine umfassenden Erfahrungen aufweist über den Einfluss so vieler mütterlicher Erkrankungen auf Leben und Organe des Kindes. Wir müssen uns daher begnügen, alle diese Thatsachen aneinander zu reihen und sie zur weiteren Förderung vorläufig unter einen einheitlichen Gesichtspunkt zu bringen.

Als, eine fernere Ursache des habituellen Absterbens ist endlich die chronische Metritis angegeben worden. Nur ein Beispiel liegt aus der Literatur dafür vor; doch möge dasselbe in Kürze angeführt sein, da jedenfalls mit Recht diese chronische Erkrankung der Mutter, wie wir sehen werden, jenes Einflusses angeklagt wird. Abarbanell') beobachtete einen Fall habituellen Absterbens, in welchem er eine syphilitische Infection gänzlich in Abrede stellte. Eine Frau, die zehn Jahre lang nach ihrer ersten Entbindung wegen einer damals zurückgebliebenen chronischen Metritis unfruchtbar war, wurde nach endlicher Beseitigung dieses Uebels wiederholt schwanger, trug aber die ersten vier darauf folgenden Kinder nicht aus, sondern abortirte erst zwei Mal und gebar die beiden letzten Kinder im 6. und 7. Monate. Erst die 5. Schwangerschaft führte zur Geburt eines lebenden gesunden Kindes.

Der wiederholte Abort in Folge von chronischer Metritis ist hinlänglich bekannt, und der Grund desselben ist gewiss oft in den Schwankungen der Blutfülle der Gebärmutterschleimhaut und des Uterusparenchyms zu finden, welche leicht zu Blutungen unter die Eihäute Anlass geben können.

Der obige Fall aber mit chronischer Metritis und habituellem Absterben in späte rer Schwangerschaftszeit lässt auch eine andere Erklärung noch zu. Häufig genug nämlich treten im Gefolge der chronischen Metritis Veränderungen des Gebärmutterparenchyms auf, welche, wie Veit ${ }^{2}$ ) sagt, an sich der Conception nicht hin-

1) Monatsschr. für Geb. 19, S. 106.

2) Lehrbuch der Krankheiten der weibl. Sexualorgane, S. 369. 
derlich zu sein brauchen. Bestehen aber diese Veränderungen, wie es nicht selten geschieht, in mässiger oder partiell stärkerer Bindegewebswucherung, die eine Verminderung oder Zusammendrängung des Muskelapparates herbeifuhrt, so ist die Ausdehnung des schwangeren Uterus in Verlaufe der Gravidität an diese pathologischen Zustände gebunden und die für das Wachsthum nothwendige Elasticität und Dehnbarkeit auf ganz bestimmte Grenzen der Ausdehnungsfähigkeit angewiesen. Warum soll sonach durch solche rein mechanische Verhältnisse die Schwangerschaft und zwar zu ungefähr gleichen Zeitpunkten nicht unterbrochen werden, und die Muskulatur des Uterus nach Entfernung aller Entzündungserscheinungen in späteren Schwangerschaften ihre normale Dehnungsfähigkeit und Spannkraft nicht wieder erlangt haben können? Ein lehrreiches Beispiel, das hierher gehört, erzählt Baudeloc $\mathrm{ue}^{\mathbf{1}}$ ) von einer Frau, welche nach überstandenem Kaiserschnitte vier Mal danach im 7. Monate gebar. Die Ursache daron. lag offenbar nur in dem narbigen Uterus; und gerade wie in diesem Falle die veränderte anatomische Structur die für die Schwangerschaft volle Ausdehnungsfähigkeit nicht mehr haben konnte, so lässt sich auch eine gleiche Folge vom chronisch entzündeten und veränderten Uterus erwarten.

Noch sind drei Fälle ats Tabelle I erwähnenswerth, welche leider nur kurze Notizen enthalten. Sie geben keinen Sectionsbefund der Kinder oder der Placenten, sagen nichts über eine eventuelle Todesursache der Früchte, noch über die Gesundheitsverhältnisse der Eltern oder nur der Mutter. Und doch enthalten diese Fälle einige übereinstimmende Merkmale. Im ersten Falle (d'Outrepont, Tab. I, Nr. 3) gebar die Frau in den ersten sieben Schwangerschaften todte Frïchte im 7. Monate, in den beiden anderen Fällen dagegen (Kilian und Hohl, 6 u. 7) jede die sieben ersten Kinder im 10. Monate. Von den ersten beiden Frauen (Nr. 3 und 6 ) ist angegeben, dass jede, die eine nach einer Pause von zwei Jahren (Enthaltung vom Beischlaf wegen längerer schwächender Krankheit des Mannes), die andere nach einer Pause von drei Jahren von dem gleichen Manne ein, resp. drei lebende reife Kinder zur Welt brachten, während von der Frau in Hohl's Falle (Nr. 7) sich nur die Mittheilung findet, dass sie ihr achtes Kind ebenfalls lebend und rechtzeitig geboren

1) Anleitung zur Entbindungskunst. II. S. 323. - Kelsch, De partu praematuro. 1824. 
hat. Es zeigt sich hier der bemerkenswerthe Umstand (ebenso wie in Nr. 2 u. 5), dass auf eine längere Ruhe und Kräftigung und Vermeidung der lokalen Reize der Genitalien in vier Fällen das habituelle Absterben wie augenblicklich abgeschnitten war. Dieser Frfolg ist gewiss kein zufälliger, und man kann auf Grund desselben (in Uebereinstimmung mit $\mathrm{Hohl}^{1}$ ) annehmen, dass doch entweder die früheren, so schnell aufeinanderfolgenden Schwangerschaften, oder, z. B. wie d'Outrepont angiebt, der zu häufige Coitus während der Schwangerschaft, also Schwächungen des Uterus oder lokale intercurrente Reize und $\mathrm{Hy}$ perämieen oder eine individuell erhöhte Reizbarkeit den Tod der Früchte und die Frühgeburten eingeleitet haben.

Betreffs der letzteren sagt Schröd er (Lehrbuch S. 419), dass sie unzweifelhaft vorkommt und derart eine Disposition zum Abortus mit sich führt, dass bei gesundem Ei und gesunden mütterlichen Genitalien Anlässe, wie geringe körperliche und geistige Aufregung, die von der grossen Mehrzahl der Frauen ohne allen Schaden ertragen werden, eine Unterbrechung der Schwangerschaft herbeiführen. Bei diesen Individuen reagiren die motorischen Nerven des Uterus auf Anlässe, die für gewöhnlich vollständig ohne Folgen bleiben.

Ich versäume nicht, im Anschluss hieran auf zwei höchst interessante, von John Barlow ${ }^{2}$ ) beobachtete Fälle aufmerksam zu macher, in denen als Folge der wiederholt vorhergegangenen künstlichen Erregung der Geburt, im 7. Monate eine gleichsam habituell gewordene Frühgeburt eintrat.

Was endlich den retzten, von Maydell beobachteten Fail (Nr. 19) anbelangt, so lässt sich dem Referat darïber so wenig entnehmen, dass er nach keiner Richtung verwerthbar ist. Nach

1) Die Geburten missgestalteter, kranker und todter Kinder. Halle 1850 , Seite 358: „Das habituelle Absterben erfolgt 6. 7. 8. 9. Monate der Schwangerschaft, auch erst in den letzten 14 Tagen derselben. Nach unserer Ansicht stehen die folgenden Fälle mit dem ersten in Verbindung, insofern nämlich der Uterus, wenn er einmal nur bis zu einer bestimmten Grenze seiner Entwickelung in der Schwangerschaft gekommen ist, diese Grenze in folgender Schwangerschaft nicht überschreitet, kommen nicht neue Verhältnisse hinzu, die seine Entwickelung steigern und ihn über jene Grenze hinaustreiben. Dies bedingt auch in manchen Fällen den habituellen Abortus. Schwäche des Uterus, vorzüglich in Folge häufigen Beischlafs, zu schnell sich folgender Schwangerschaften mag oft Veranlassung geben."

2) Reisinger, Die künstliche Frühgeburt. Augsburg und Leipzig, 1820. S. 151. 
dreimaligem Fruchttod wurde in der 4. Schwangerschaft bei zweimaligem drohenden Absterben ein Aderlass angewandt, nach dem die schon verminderten Kindesbewegungen wieder lebhaft wurden. In der 38. Woche wurde ein kräftiges, lebendes Kind geboren.

Fassen wir nun alle diese Beobachtungen zusammen, so lassen sie sich in folgenden Sätzen ausdrücken:

1) Das habituelle Absterben der Früchte beruht sicher in den meisten Fällen auf syphilitischer Erkrankung der Eltern.

2) Die Symptome dieser Ursachen werden entweder bei frühem Absterben am Foetus gänzlich vermisst, der Foetus wird todtfaul ausgestossen, und dieser todtfaule Zustand oder der Hydrops sanguinolentus Martin ist dann nicht als die eigentliche fötale Erkrankung, sondern nur als eine dem todten Organismus zukommende Erscheinung aufzufassen, oder

3) der Foetus wird in den letzten Monaten oder gegen das Ende der Schwangerschaft oder selbst reif geboren, in der Mehrzahl der Fälle dann für kurze Zeit lebend, in der Minderzahl tief asphyktisch oder todt, und dann sind die Zeichen der angeborenen Lues meistens zu sehen, entweder allein in den verschiedensten Organen des Foetus oder auch gleichzeitig oder nur in der Placenta, den Eihäuten oder im Nabelstrange.

4) Habituelles Absterben der Frucht kann allein auf Syphilis des Vaters beruhen, und hört bisweilen auf, wenn die Frau eines solchen Mannes zum zweiten Male mit einem völlig gesunden und kräftigen Manne verheirathet ist.

5) Wichtige Gründe machen es in hohem Grade wahrscheinlich, dass auch die Anämie oder Blutanomalieen der Mutter (wie durch Intermittens) die Frucht intrauterin in den letzten Wochen der Schwangerschaft absterben lassen; doch sind noch ausführlichere Beobachtungen hierüber erforderlich, vor Allem genaueste Mittheilungen ïber Frucht und Eitheile.

6) Bei eventuellen solchen Beobachtungen kann die Bemerkung: Vater gesund, Mutter sehr anämisch, keinesfalls dem Einwurfe der Syphilis gegenüber genügen. Die Angabe der positiven Gesundheit des Vaters muss sich auf genaue Anamnese und Untersuchung gründen.

7) Auch chronische Gebärmuttererkrankungen und - reizungen, besonders die chronische Metritis, und eine allgemeine individuelle Reizbarkeit können den habituellen Fruchttod bewirken. Doch erfordert auch dieser Punkt 
noch solche Belegfälle, welche mit absoluter Sicherheit Lues der Eltern ausschliessen können.

8) Höchst wahrscheinlich können auch wiederholte Erkrankungen der Placenta und der Gefässe des Nabelstranges (z. B. Stenosen), ohne zu Grunde liegende Syphilis, habituelles Absterben der Frucht herbeiführen.

Bei der grossen Verwirruug, welche über das Kapitel des habituellen Absterbens herrscht, war es nöthig; so eingehend zunächst alle möglichen Verhältnisse zu sichten, und es wird jetzt leichter sein, auch in dem in der Einleitung mitgetheilten Falle die wirkliche Ursache kritisch zu beleuchten.

$\mathrm{Da}$ in diesem Lues auszuschliessen ist, die Mutter aber an bedeutender Anämie litt, so kann nur diese letztere als Ursache des habituellen Absterbens angenommen werden.

Dann ist freilich von Seiten der letzten Frucht die Stenose der Nabelvene in hohem Grade bemerkenswerth, insofern als dieselbe mit der mütterlichen Anämie jedenfalls in einem noch unklaren Zusammenhange steht.

Winckel ${ }^{1}$ ) hat sechs Fälle von primärer Stenose der Nabelvene beobachtet, und betrachtet dieselbe als hauptsächlichste Ursache des Absterbens der Frucht in diesen Fällen. Nur in einem derselben war Syphilis mit Bestimmtheit nachweisbar, doch hält er auch in den übrigen die Venenerkrankung für syphilitischen Ursprungs. Seine Fälle betreffen vier Erst- und zwei Mehrgebärende, in dem meinen eine Fünftgebärende; dort wurden mit dieser Stenose zwei Früchte in der 20.-28. Woche, und vier in der 30.-36. Woche geboren; in meinem Falle am rechten Ende der Schwangerschaft. Dieser letztere Umstand spricht jedenfalls deutlich dafür, dass sich die Stenose auch nur erst in der kürzesten Zeit vor Einleitung der Frühgeburt ausgebildet haben kann. Denn die Frucht war kräftig, gut genährt, wohlgebildet und lebend. Es spricht ferner dafür, dass bei nicht unterbrochener Schwangerschaft auch diese Frucht intrauterin noch abgestorben wäre, während mit der grössten Wahrscheinlichkeit anzunehmen ist, dass bei vielleicht zwei Tage früher, bei Eintritt der ersten drohenden Symptome des Absterbens eingeleiteter Frühgeburt die Frucht nicht asphyktisch, sondern frisch geboren, und

1) Berichte und Studien aus dem königl. sächs. Entbindungsinstitut in Dresden. Leipzig, Hirzel. 1874. 
am Leben erhalten worden wäre. Auch Bireh-Hirschfeldy) hat in der jüngsten Zeit einen Fall von Stenose der Nabelvene beobachtet, deren Aetiologie durch eine complicirende syphilitische Epiphysenerkrankung sofort gegeben ist. Wie Birch-Hirschfeld hierbei erwähnt, haben auch schon Oedmanson und Winckel betont, dass man keineswegs in allen Fällen, wo es sich um todtfaule Früchte handelt, solche Gefässveränderungen in der Nabelschnur auffinden kann, nach H.'s Erfahrung nicht einmal in der Mehrzahl der todtfaulen Früchte mit exquisit syphilitischer Knochenveränderung. Andererseits ist es Birch-Hirschfeld aufgefallen, dass er mehrmals die circumscripte Gefässstenose vorgefunden hat, wo sich die Epiphysen völlig normal darstellten, es handelte sich um todtfaule Früchte, deren Entwickelung dem 7. Monate entsprach.

Auf diesen letzteren Passus mache ich deshalb aufmerksam, als leider in meinem Falle auf besonderen Wunsch die Epiphysenuntersuchung unterbleiben musste.

Haben wir demnach auch keine Erklärung für die primäre Nabelvenenstenose in meinem Falle, so sprechen auch Winckel's Fälle sämmtlich noch nicht zwingend für syphilitischen Ursprung, und die Frage ist noch als eine offene zu betrachten, in welcher Abhängigkeit eine derartige Affection der Nabelvene vom mütterlichen Organismus steht.

\section{II.}

Welche Ansichten der Autoren existiren über den habituellen Tod als Anzeige zur künstlichen Frühgeburt, und welche Erfahrungen liegen über die Erfolge dieser Operation in dieser Hinsicht vor?

Wenden wir uns jetzt zur Beantwortung dieser zweiten Frage, so ist es am zweckmässigsten, das pro und contra anzuhören und die verschiedenen Urtheile in zwei Parteien zu theilen.

Eine Anzahl namhafter Autoren hat sich mehr weniger bestimmt dagegen ausgesprochen, in dem habituellen Absterben eine Anzeige zur künstlichen Frühgeburt zu erblicken.

Nachdem Denman zu Ende des vorigen Jahrhunderts zuerst, wie Krause sagt, auf den glücklichen Gedanken gekommen war,

1) 1. c. - cf. Allgem. med. Centralzeitung. 1875. Nr. 26. 
durch die künstlich herbeigeführte Geburt dem habituellen Absterben der Früchte kurz vor beendeter Schwangerschaft zuvorzukommen, wendete sich als einer der ersten Reisinge $\mathbf{r}^{\mathbf{1}}$ ) gegen ihn.

Hofmann ist, wie wir später sehen werden, auf die Gegengründe Reisinger's ausführlich eingegangen; es sei darum auf seine Worte weiter unten specieller verwiesen.

Martin und Bonnekamp2) meinen übereinstimmend, entsprechend ihrer Annahme, dass das habituelle Absterben fast immer nur Folge der fötalen Erkrankung: des Hydrops sanguinolentus sei, es werde bei dieser Ursache die künstliche Frühgeburt nichts nützen, vielmehr sei eine consequente antisyphilitische Cur der Eltern vor einer nenen Zeugung das einzig wirksame Mittel, der Wiederkehr vorzubeugen.

Nicht so entschieden dagegen erklären sich Döbner und Scanzoni, welche als Ursachen ausser der constitutionellen Syphilis auch die Anämie der Schwangeren annehmen. Zunächst sagt Döbner: ,Fast allgemein wird das habituelle Absterben der Kinder als Indication aufgestellt. Allein abgesehen davon, dass wir mit diesem Ausdrucke keinen bestimmten Begriff verbinden, sondern gewissermassen nur unsere Unkenntniss der Ursache des Absterbens bemänteln, kann die künstliche Frühgeburt, selbst mit dem besten Erfolge ausgeübt, deshalb nicht mit Bestimmtheit als Grund der Rettung des kindlichen Lebens angesehen werden, weil schon öfter nach wiederholten unglücklichen Frühgeburten doch ein oder mehrere lebende Kinder rechtzeitig geboren wurden. Mag daher Syphilis oder Chlorose die Ursache des Absterbens der Früchte sein, so ist es jedenfalls zweckmässiger, so früh als möglich eine gegen diese Krankheiten gerichtete Therapie einzuschlagen, als auf den unsicheren Erfolg der künstlichen Frühgeburt zu warten. Das habituelle Absterben wird demnach die letztere nur selten indiciren."

Es kehrt auch in diesen Worten derselbe Gegengrund wieder, den schon Reisinger angeführt hat, dass das Kind auch ohne Frühgeburt im gegebenen Falle nicht zu Grunde gehen muss. Auch Scanzoni räth, in den erwähnten Verhältnissen nicht eine unbedingte Anzeige für die künstliche Frühgeburt zu erblicken,

1) 1. c.

2) Mon. f. Geb. 19, S. 86. 
sondern durch ein die Ursache des Absterbens beseitigendes therapeutisches Verfahren einen ungestörten Schwangerschaftsverlauf herbeizuführen.

Spiegelberg ') ferner sagt, dass die Indication des habituellen Absterbens als widersinnig ganz zu verwerfen sei. „Denn da dieses auf erblicher Syphilis beruht, und diese durch Unterbrechung der Schwangerschaft nicht getilgt wird, so ist es ja gleichgültig, $o b$ das Kind ungeboren oder geboren abstirbt. Es stirbt doch."

Endlich spricht sich auch Litzmann ${ }^{2}$ ) gegen diese Indicacation aus, die er niemals als eine berechtigte anerkannt habe.

Mit eben so treffenden Gründen aber sind Andere für diese Indication eingetreten. Unter den Engländern zunächst sind es Denman, Simpson und Barnes. Indem ich den Ersten als den Urheber übergehe, da er, wie es scheint, keine specielleren Gründe für sein Eingreifen angegeben hat ${ }^{3}$ ) - obschon er zwei Kinder rettete, ohne dabei die Mütter im Geringsten zu gefährden - ist von Simpson zu erwähnen, dass er in den Fällen die künstliche Frühgeburt unbedingt angezeigt fand, wo nach seiner Ansicht, und nach der Erfahrung früherer Schwangerschaften, Placentarerkrankungen zu. Grunde lagen, - mithin Fälle, die nach S.'s damaliger Ansicht frei von Syphilis waren. In zwei derartigen Fällen wendete er mit glücklichem Frfolge für Mutter und Kind die künstliche Frühgeburt an (s. Tabelle II); in einem dritten, den er ohne Operation lassen wollte, kam im achten Monate ganz von selbst die Frühgeburt mit einem lebenden Kinde zu Stande. Die zugehörige Placenta war "so destroyed by inflammatory induration, that it could not have served the purpose of a lung to the child for a much longer period."

Auch Barnes hat sich bei Gelegenheit der Discussion über Hayes's Fall aus gleichem Grunde entschieden für die Einleitung der Frühgeburt ausgesprochen. Vierzehn Mal nach einander (4,-17. Schwangerschaft) war die Frucht (zuerst im siebenten, das letzte Mal im zehnten Monate) abgestorben; die Nachgeburt der letzten befand sich in hochgradiger Verfettung, in Folge deren

1) Mon. f. Geb. 34. S. 376.

2) Dieses Archiv II. S. 169.

3) Das Original war mir leider nicht zugänglich. 
nach Barnes der intrauterine Tod eintrat. Bei neuer Schwangerschaft sei, um dem zu entgehen, die künstliche Frühgeburt unbedingt nothwendig.

Schon oben wurde erwähnt, dass die Placentarpathologie Simpson's nach den Untersuchungen Fränkel's vielfach auf elterlicher Syphilis beruhe und wohl kaum Erkrankungen sui generis seien. Wenn man jedoch aus Simpson's kurzer Angabe im Texte annehmen darf, dass die Kinder lebend geboren wurden und am Leben blieben, so kommt die eltérliche Lues als Grundkrankheit sehr in Zweifel, und die Placentarerkrankungen behalten als selbstständige Krankheiten entschieden ihr Recht, und dürfen die künstliche Frühgeburt als Rettungsmittel der Kinder erheischen.

Unter den Deutschen vertheidigt $\left.\mathrm{Kelsch}^{1}\right)^{\prime}$ zuerst das habituelle Absterben als Anzeige zur kïnstlichen Frühgeburt. Nachdem er die später anzuführenden Gegengründe Reisinger's als theilweise berechtigt erwähnt und kritisirt hat, sagt er mit Celsus: melius esse anceps adhiberi remedium, quam nullum, und betont, dass die Operation nicht allein den Müttern nicht schade, sondern auch, wie viele Beispiele lehren, oft genug gesunde Kinder zur Welt bringe.

S chippa ${ }^{2}$ ) pflichtet den Ansichten Kelsch's vollständig bei und fasst dieselben in die knappen Worte zusammen: „Nach Kelsch ist das habituelle Absterben nur dann Anzeige zur kïnstlichen Frühgeburt, wenn nach vorhergegangenen mehrmaligen Fehlgeburten allemal zu einer bestimmten Zeit gegen das normale Schwangerschaftsende hin vergebens denselben durch ärztliche Behandlung Einhalt gethan wurde, und das Kind jedes Mal abstarb. Hier soll man, nachdem mán sich von dem Leben des Kindes vollständig überzeugt hat, einige Tage vor diesem gefährlichen Zeitpunkte, nach Verlauf der 28. Schwangerschaftswoche zur möglichen Erhaltung des Kindes die künstliche Frühgeburt erregen, wenn anders das Befinden der Mutter keine Gegenanzeige für diese Operation abgiebt."

In gleichem Sinne spricht sich Fuhrhans aus, und ausführlich besonders betreffs der Zeit, in der die Frühgeburt einzuleiten ist. Vor Allem seien die Grundkrankheiten zu behandeln, der Organismus der Mutter sei zu kräftigen; prophylaktisch aber

1) De partu arte praematuro. Diss. inaug. Berlin, 1824.

2) Ueber die künstliche Frühgeburt. Würzburg, 1831. 
halte er die künstliche Frühgeburt angezeigt, und zwar hänge sie von der Zeit $a b$, in der früher die Früchte abgestorben sind. Wenn die Früchte gut ernährt zu früh geboren worden wären, so sei anzunehmen, dass die Entwickelung des Kindes durch keine schwere Störung aufgehalten worden sei. In einem solchen Falle sei daher die Frühgeburt 14 Tage oder besser 3-4 Wochen vor der Zeit des Todes der früheren Früchte einzuleiten. Keinesfalls aber vor der 28. Schwangerschaftswoche (1). Besonders könne in Fällen von ererbter Disposition zum habituellen Absterben der Früchte nur. von dieser Operation Heil und Rettung erwartet werden.

Am eingehendsten wohl hat sich Hofmann ) mit dem pro und contra des habituellen Absterbens beschäftigt; und da er auf die theilweise erwähnten Ansichten kritisch eingeht und nach allseitiger Abwägung sich mehr auf die Seite des für legt, so ist wohl seinen treffenden Worten ein etwas grösserer Raum zu gönuen: „Das Absterben des Kindes kommt bei manchen Frauen, ja selbst bei mehreren weiblichen Gliedern ein und derselben Familie fast habituell vor, so dass es scheint, dass der Uterus gewisser Frauen nicht die Fähigkeit besitzt, den Process der Schwangerschaft ganz zum normalen Ende zu führen.

Es ist nicht zu läugnen, dass die Operation der künstlichen Frühgeburt einen wahren Triumph feiern würde, wenn es ihr gelänge, noch ähnliche Fälle wie die Denman'schen aufzuweisen und das Leben des Kindes zu erhalten; allein mehrere Gründe scheinen gegen eine so weite Ausdehnung des Terrains der künstlichen Frühgeburt zu sprechen.

a) Der erste und wichtigste Einwurf, auf den schon Reising e r aufmerksam gemacht hat, ist ohne Zweifel der, dass man nicht Brief und Siegel hat, ob, auch wenn schon mehrere Schwangerschaften hintereinander ein ähnliches unglückliches Ende genommen haben, dies auch in der jetzt bestehenden Schwangerschaft der Fall sein wird. Die Erfahrung lehrt, dass, auch wenn bei 3,4 , 5 und noch mehr aufeinander folgenden Schwangerschaften das Kind allemal abstarb und zu früh geboren wurde, nichts destoweniger nun die sechste Schwangerschaft ihr normales. Ende erreichte. Wer bürgt dafür, dass dies nicht auch jetzt

1) Ueber künstliche Frühgeburt. Neue Zeitschr. für Geb. 14, S. 367. 
der Fall sein werde? Allerdings ein gewichtiger, doch, wie uns wenigstens dünkt, nicht unwiderlegbarer Einwurf! Wir möchten: diesen Einwurf vor Allem dadurch zurückweisen, dass wir ja in der gesammten Heilkunde in so ausserordentlich vielen Fällen keine absolute Gewissheit haben, sondern dass sehr oft die Allalogie und die Wahrscheinlichkeit das Handeln bestimmen muss.

Wir wollen indess hiermit keineswegs den Grundsatz aufstellen, sobald das eine oder das andere Mal das Kind während der Schwangerschaft abstirbt, gleich zur künstlichen Frühgeburt greifen zu sollen, sondern halten uns im Gegentheile streng an die Worte Denman's. Ein ein- oder andermaliges Absterben des Kindes ist noch kein habituelles Absterben des Kindes in der Schwangerschaft; letzteres tritt erst dann ein, wenn wir durch eine Reihe von Schwangerschaften überzeugt sind, dass das Kind allemal und jedesmal abstirbt, und daher scheint uns die Modification, welche $\mathrm{Kelsch}$ dieser Indication beifügte, und die darin besteht, dass dieses habituelle Absterben der Früchte nur dann Anzeige der künstlichen Frühgeburt werden könne, wenn nach vorhergegangenen, mehrmaligen Fehlgeburten allemal zu einer bestimmten Zeit gegen das normale Schwangerschaftsendehin vergebens demselben durch ärztliche Behandlung entgegengearbeitet wurde, und das Kind jedes Mal abstarb, wohlgegründet zu sein.

b) Ein zweiter, minder wichtiger gegen diese Indication gemachter Einwurf ist: es sei nicht wohl möglich, einen Zeitpunkt zu bestimmen, wenn die künstliche Frühgeburt gemacht werden solle. - Dieser Einwurf ist begründet, sobald der Zeitpunkt, wann der Foetus abstirbt, nicht immer derselbe ist, sondern variirt. Allein wenn dieser Zeitpunkt des Absterbens sich immer gleich bleibt, so ist nicht abzusehen, warum man nicht wissen sollte, wann zu operiren ist. Kurze Zeit, bevor noch der zu befürchtende Augenblick herangenaht ist, wird und muss wohl der günstigste Moment sein, wenn wir nach Vernunft und therapeutischen Principien die fragliche Operation unternehmen sollen. Wichtiger als dieser zweite Einwurf scheint wohl

c) der Einwurf zu sein, dass es durch sorgfältige therapeutische und diätetische Pflege manchmal gelingt, den befürchteten Zeitpunkt vorüber und die Schwangerschaft $\mathrm{zu}$ ihrem normalen Ende zu führen, wie es d'Outrepont ${ }^{1}$ ) einmal gliicklich gelang.

1) Ulsamer, $1 \mathrm{c}$. 
Wenn dieses allemal oder wenigstens in der Mehrzahl der Fälle gelänge, so wäre die künstliche Frühgeburt eine nutzlose Handlung, wo nicht gar schädlich. Allein diese Beobachtung d'Outrepont's steht bis jetzt als eine Ausnahme von der Regel da, und scheint daher nicht geeignet, diese Indication zu verwerfen. Sollten fernere Beispiele die Möglichkeit und die Mittel und Wege zeigen, diesen gefürchteten Punkt der Schwangerschaft schadlos vorüberzuführen, so wäre gewiss dieses noch zu erfindende Verfahren einzuschlagen und das habituelle Absterben der Kinder nicht mehr als Indication gelten zu lassen.

d) Endlich die letzte gegen diese Indication erhobene Anklage lautet: Der Organismus des Weibes, deren Schwangerschaft stets durch die erwähnten Zufälle gestört wird, scheint zu leidend, um einen solchen Kunsteingriff für das Leben der Mutter wagen zu können. Vom theoretischen Standpunkte ist hiergegen nichts einzuwenden; denn es scheint gewagt, einem zu Fehlgeburten geneigten Weibe, mit erkranktem Genitalsysteme, auch noch die künstliche Frühgeburt aufzubürden. Die Erfahrung zeigt jedoch mit wenigen Fällen, in denen habituelles Absterben des Foetus die Indication für die künstliche Frühgeburt abgab, dass diese Befürchtung unbegründet ist. In den beiden Denman'schen Fällen resultirte wenigstens für die Mutter kein Nachtheil daraus.

Fassen wir diese vier, gegen die benannte Indication rorgebrachten Einwürfe zusammen, so scheinen sie sämmtlich nicht ron dem Gewichte zu sein, um diese Indication null und nichtig zu machen. Es sind aber über diesen Punkt die Acten noch nichts weniger als für geschlossen anzusehen, sondern es müssen erst weitere Erfahrungen und Beobachtungen lehren, ob das habituelle Absterben der Kinder im Mutterleibe. während der Schwangerschaft definitiv unter die Reihe der Indicationen für die künstliche Frühgeburt zu stellen sei oder nicht. Bis dieses der Fall ist, scheint der Rath, den Kelsch gab, diese Indication gelten zu lassen, wenn wiederholte Schwangerschaften gezeigt haben, dass allemal zu einer bestimm ten Zeit der Schwangerschaft das Kind abgestorben, der befolgungswerthe Ausweg zu sein.

$\mathrm{Zu}$ diesen Worten sind zunächst einige Bemerkungen zu machen, welche Hofmann noch mehr veranlassen können, jene Indication zu befürworten.

Erstens sind im Laufe der Zeit jene Fälle Denman's nicht 
allein geblieben; es hat sich ihnen eine ganz achtbare Reihe neuer angeschlossen (s. Tab. II):

Zweitens zeigen gerade diese Fälle, und darunter eine Anzahl mit gutem Ausgange für Mutter und Kind, dass der Termin zur Einleitung der Frühgeburt recht wohl sich bestimmen lässt. Drittens haben allerdings noch Andere, ausser d'Outrepont (nämlich Kilian, Kaufmann), die Beobachtung gemacht, dass therapeutisclie und diätetische Pflege manchmal die Schwangerschaft zu ihrem normalen Ende führen lässt (Tab. I. Nr. 2, 3, $5,6,18)$; Andere haben aber auch das Gegentheil beobachtet (Döbner, 2. Fall, Tab. II). Es ist darum dieser Punkt, wie Hofmann sagt, trotzdem gewiss nicht geeignet, diese Indication über den Haufen zu werfen.

Viertens kann aber auch davon keine Rede sein, dass die Einleitung der Frühgeburt dem an und für sich schon leidenden Organismus der Frau schaden könne. Im Gegentheile lehren einzelne Fälle, darunter die eclatanten Beobachtungen Gusserow's, dass es die Schwangerschaft selbst sein kann, welche den Organismus schädigt, und dass darum deren Unterbrechung nur von Nutzen für die Frau ist.

Wenn ich mit diesen wenigen Worten der Beweisfubrung Hofmann's noch das Material zu Grunde gelegt habe, welches noch fehlte, als Hofmann jene Kritik schrieb, und welches seitdem sich angesammelt hat, so möchte ich mir damit meine eigenen Schlüsse noch nicht vorn hinweg genommen haben, sondern nur das Ganze allmälig auf das Endresultát hinführen.

Zunächst aber erübrigt noch die Ansicht Krause's') über das habituelle Absterben als Anzeige zur künstlichen Frühgeburt. Er ist $f$ ür dieselbe, ,denn der Nacbtheil eines Irrthums bei passivem Verhalten, sagt er, ist ungleich grösser als der beim activen. Versetzt man sich in die Lage des Kindes, dem die Wahl $z$ wischen beiden Verfahren gelassen wäre, so würde sich Jeder eher für die Chancen eines vorzeitigen Lebens als eines wahrscheinlichen Todes entscheiden."

Auch" in die neueren Lehrbücher der Geburtshülfe ist jene Indication aufgenommen worden. Zu ihren Gunsten spricht sich z. B. Schröder ${ }^{2}$ ) aus: „Man kann die künstliche Frühgeburt

1) Die künstliche Frükgeburt. S. 14.

2) Lehrbuch der Geburtshülfe. 4. Aufl. S. 235. 
gelegentlich mit Nutzen einleiten bei einer Frau, bei der die Erfahrung gelehrt hat, dass die Kinder jedesmal zu einer bestimmten Zeit der Schangerschaft absterben, wenn diese Zeit vom normalen Ende der Schwangerschaft nicht sehr weit entfernt ist und andere Mittel, um den intrauterinen Tod des Kindes zu verhindern, in früheren Schwangerschaften wirkungslos gewesen sind."

Endlich sprechen noch für die Indication die Namen aller derer, welehe wegen habituellen Absterbens auch wirklich die Frühgeburt eingeleitet haben.

Die darüber bekannt gewodenen Fälle gebe ich zunächst am übersichtlichsten in Form einer Tabelfe (S. S. 268) und knïpe hieran einige Betrachtungen.

In diesen 15 Fällen ist $16 \mathrm{Mal}$ (zwei MaI in Fall 8 von Burchard) wegen habituellen Absterbens die Frühgeburt, eingeleitet worden.

Gerade nun wie der Werth der oben erwähnten Ansichten der Autoren in der mehr weniger begründeten Ursache liegt, welche sie dem habituellen Absterben zu Grunde legen, so wird auch jetzt der Werth dieser Einzelbeobachtungen aus der jedesmaligen Ursache des Absterbens hervorgehen.

Leider aber erfahren wir recht wenig in den Fällen über die dem intrauterinen Fruchttod supponirten Ursachen. In den beiden Fällen von Simpson (Nr. 5 und 6) waren die Placenten der abgestorbenen Früchte stets erkrankt gewesen, und Simpson sah darin den Grund des wiederholten Absterbens. In Kilian's Fall (11) war das habituelle Absterben Familienfehler; in dem Falle Nr. 12 konnte Busch keinen plausiblen Grund ausfindig machen; jedoch lässt sich aus dem durch die künstliche Frühgeburt lebend erhaltenen und später von einem syphilitischen Exanthem befallenen Kinde vermuthen, dass die beiden ersten, Mitte des 10. Monates abgestorbenen Früchte vielleicht auch in Folge von Syphilis abgestorben waren. Scanzoni nimmt als Ursache in seinen beiden Fällen Anämie der Schwangeren an, und auch ich kann mich, wie ich oben gezeigt habe, für meinen Fall (Nr. 15) nur für dieselbe Aetiologie aussprechen. In den übrigen Fällen der Tabelle $(1,2,3,4,7,8,9,10)$ ist entweder kein Grund angegeben oder keiner nachweisbar gewesen. Jedoch lassen sich aus den Erfolgen dieser Fälle einzelne Bemerkungen über die eventuellen Gründe machen. Denman sowohl (Fall 1 u. 2) wie Simpson (5 u. 6) geben an, dass die Operation für Mutter und 
Kind günstig war; in Hayn's Fall (3), ,gedieh der entwickelte Knabe kräftig"; der Fall von Dubourge (4) wird ebenfalls als durchaus günstig bezeichnet; Diesterweg (10) giebt an, dass „das Kind mit der Mutter gesund blieb", und Kilian (11) nennt die Operation ein glänzendes Heilmittel. Sollte man gingstig verlaufenen Fällen an zu Grunde liegende Syphilis denken können, welche erfahrungsgemäss die lebend geborenen Kinder gewöhnlich bald entweder nach der Geburt sterben oder von ihren specifischen Symptomen später befallen werden lässt? Es ist wohl anzunehmen, dass hierüber von den Autoren, die oft ziemliche Zeit darnach diese Fälle publicirt haben, der eine oder der andere gewiss eine Notiz gegeben haben würde.

Somit bleiben nur noch die Fälle $7,8,9$ übrig. In dem ersteren derselben (Nr. 7, Herrmann) waren drei Aborte und eine Frühgeburt im 8. Monate vorausgegangen; bei der 5. Schwangerschaft wurde schon im \%. Monate die Frühgeburt eingeleitet. Das schliesslich mit der Zange entwickelte Kind kam todt zur Welt. Es wäre gewiss ganz unrecht, aus diesen Bemerkungen auch nur annähernd auf einen Grund des Absterbens hinzielen zu wollen. Denn der Fall spricht ebensowohl für elterliche Lues als für Chlorose und Anämie oder chronische Gebärmuttererkrankung, oder, wenn wir noch wollen, für eine individuell erhöhte Reizbarkeit der Mutter, als dass er nach einer Richtung hin verwerthbar wäre. Ausserdem lässt sich der Fall nicht einmal als Beispiel für habituelles Absterben heranziehen, da nur ein einziges Mal (in der 4. Schwangerschaft) die Frucht im 8. Monate abgestorben war, ganz abgesehen daron, dass auf diesen einen Fall hin es meiner Ansicht nach ganz unberechtigt war, sogleich in der nächsten (5.) Schwangerschaft, noch dazu in einer so ungünstig frühen Zeit (28. Woche) die Frühgeburt einzuleiten. Aus diesen Gründen ist dieser Fall durchaus werthlos; wenn er jedoch in obige Tabelle mit aufgenommen ist, so hat dies nur seinen Grund darin, um möglichst vollständig zu sein, und durch die Kritik solcher Fälle das Bild klarer und bestimmter zu machen.

Betrachten wir dagegen die beiden Fälle Burchard's ( 8 u. 9), so lässt sich hier eher - ich bekenne aber auch hier ganz offen, mit Vorbehalt - aus den Erfolgen ein negativer Schluss auf die Ursachen des habituellen Fruchttodes machen. In Fall 8 hatte eine Frau fünf Mal nach einander Mitte des 10. Monates todte Kinder geboren. Die 6. und 7. Schwangerschaft brachte 


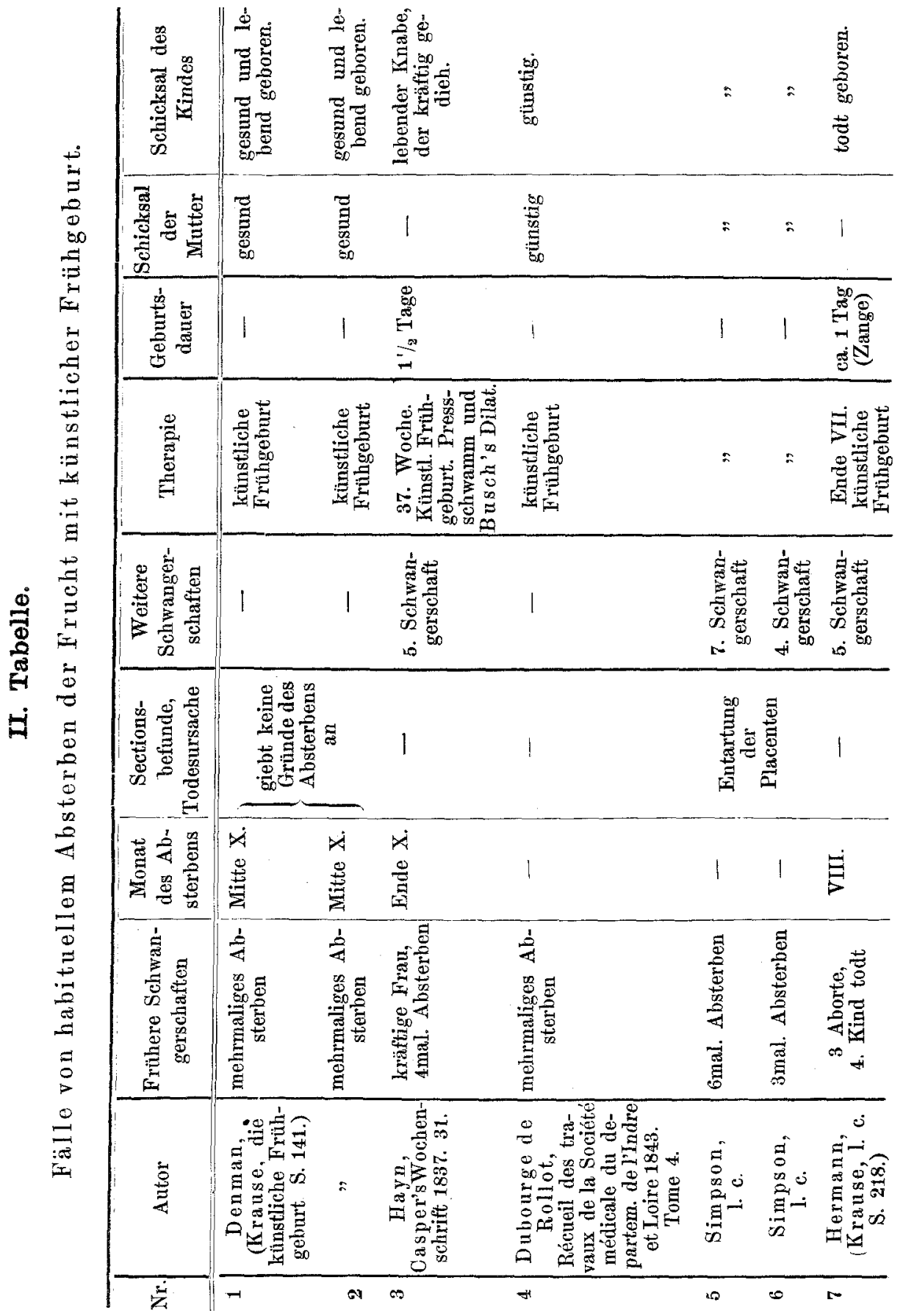




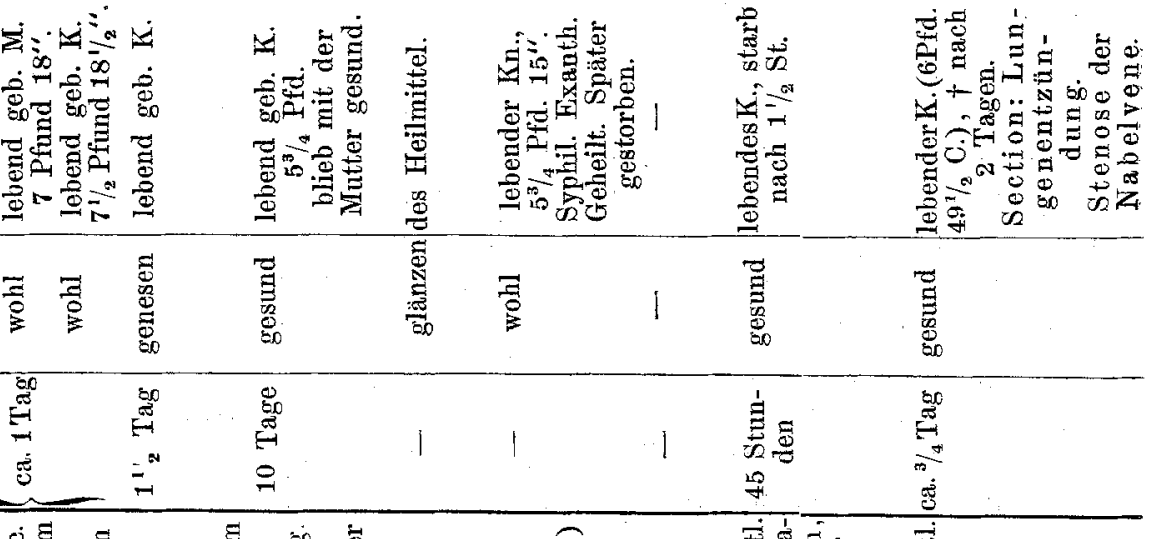

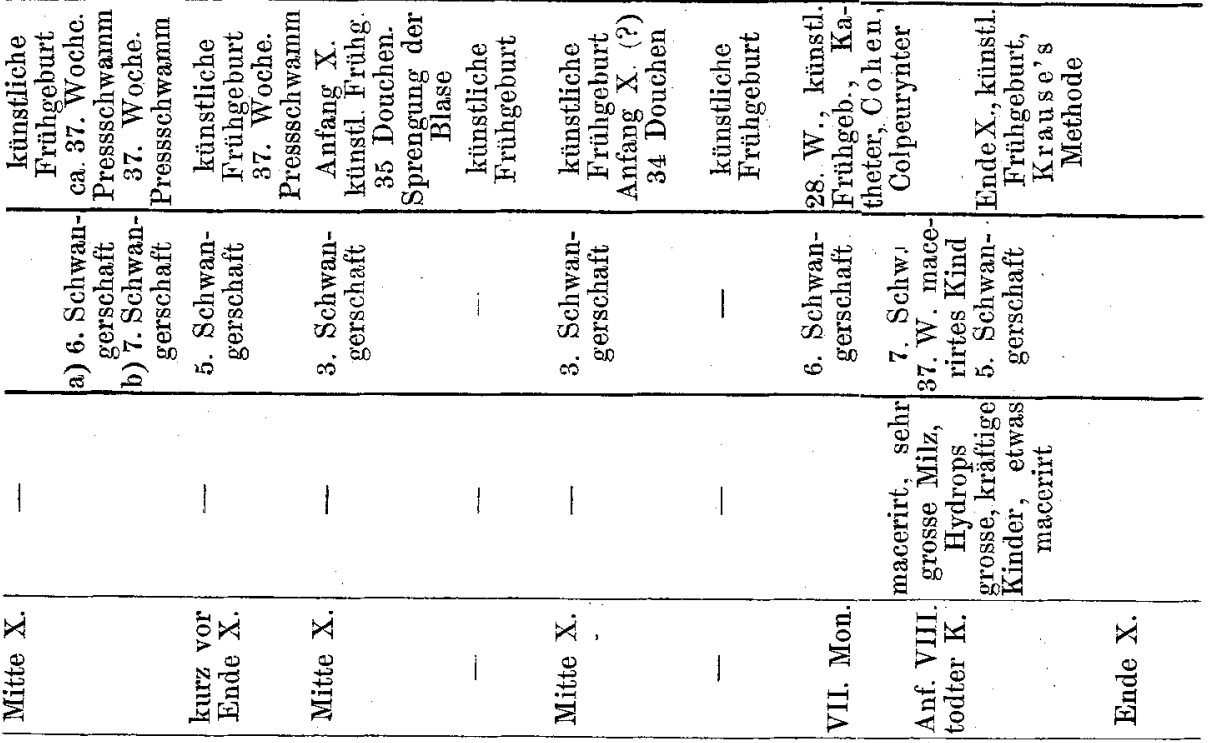

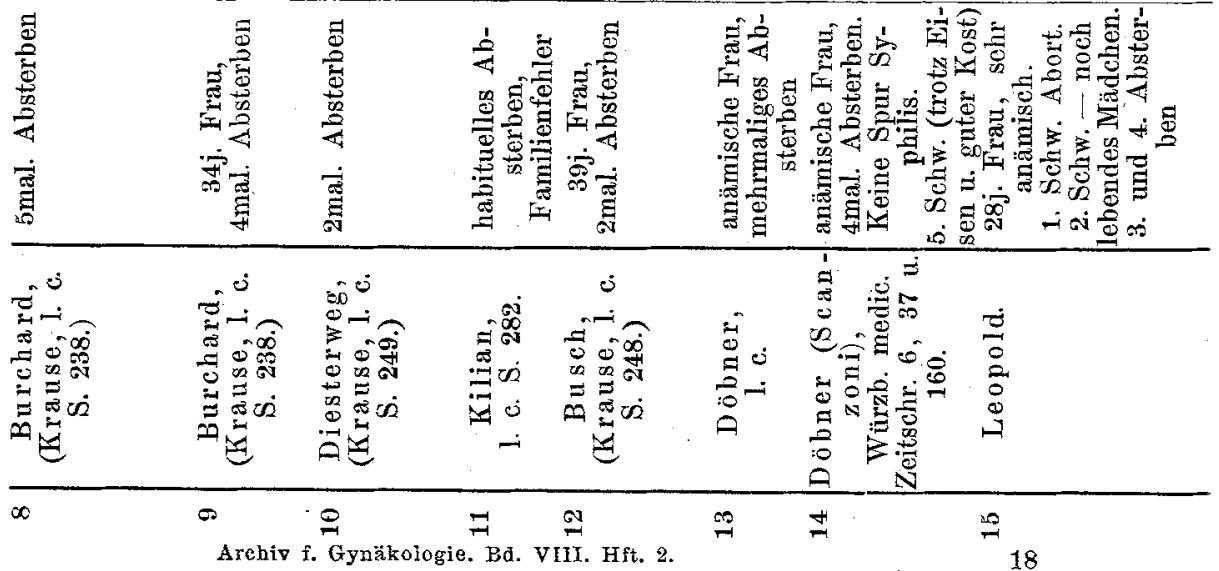


jedesmal durch die künstliche Frühgeburt in der 37. Woche lebende, grosse und kräftige Kinder zur Welt, von $7-71 / 2$ Pfund und 18-18\% Zoll Länge. Und der neunte Fall erzählt von einer Frau, die nach viermaligem Absterben der Kinder kurz vor dem normalen Ende der Schwangerschaft ebenfalls in der 37. Woche durch die Einleitung der Frühgeburt einen lebenden Knaben gebar, über dessen Entwickelung freilich nichts angegeben ist. Diese beiden Fälle, besonders Nr. 8, machen es theils durch das regelmässige Absterben der Kinder erst kurz vor dem vollen Schwangerschaftsende und theils durch die kräftige Entwickelung der Früchte ganz unwahrscheinlich, dass das frühere Absterben etwa durch Syphilis hervorgerufen war; hier sind weit eher andere Ursachen glaubhaft, z. B. die von Kilian u. A. angenommene ererbte Disposition, oder irgend welche andere körperliche $\mathrm{Zu}$ stände, die uns vorläufig noch unklar oder den bisherigen Untersuchern entgangen sind.

Schliessen wir somit den Fall 7 von Herrmann nothwendigerweise aus, so bleiben noch 14 Fälle mit 15 Mal eingeleiteter Frühgeburt, unter denen nur ein einziger positiv sicherer Fall ist (Busch), wo dem habituellen Absterben Syphilis zu Grunde gelegen hat.

Betrachten wir nun diese 14 Fälle weiter nach den früheren Schwangerschaften, so fand sich

mehrmaliges Absterben der Früchte in 5 Fällen (Nr. 1, 2, 4, $11,13)$,

\begin{tabular}{|c|c|c|c|c|c|}
\hline zweimaliges & , & ', & g &, $3 \quad$, & $(\mathrm{Nr} .10,1215)$ \\
\hline dreimaliges & "9 & , &, & , 1 Fall & (Nr. 6), \\
\hline viermaliges &, & , &, & , 2 Fällen & (Nr. 3, 9), \\
\hline fünfmaliges & "' & " & , & " 2 ," & (Nr. 8, 14), \\
\hline sechsmaliges & , & , & , & , 1 Fall & (Nr. 5). \\
\hline
\end{tabular}

Von der Zeit, in der der habituelle Fruchttod eingetreten war, ist nur in neun Fällen etwas angegeben. Stellen wir daneben, wie oft zu derselben Zeit der Tod erfolgt war, so ergeben sich folgende Verhältnisse:

In 1 Falle (Nr. 14) erfolgte fünfmaliges Abst. Ende VII Anf. VIII.
In 5 Fällen (Nr. 1, 2, $\left\{\begin{array}{l}\text { mehrmaliges (2 Fälle) } \\ \text { zweimaliges (2 Fälle) }\end{array}\right.$ Mitte X. $10,12,8)$ erfolgte $\left\{\begin{array}{l}\text { zweimaliges } \\ \text { fünfmaliges }(1 \text { Fall })\end{array}\right.$

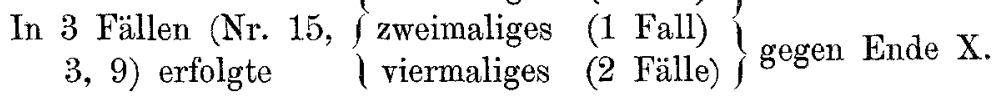


Die Frühgeburt wurde nun in sieben von diesen neun Fällen zu folgender Zeit eingeleitet:

Nach Absterben Ende VII-Anf. VIII, eingeleitet in d. 28. Woche (Nr. 14).

Nach Absterben Mitte X, 3 Mal eingeleitet in der 37. Woche (Fall 8 zwei Mal),

(Nr. 8, 10 und 12), (Nr. 1, 2 ?).

Nach Absterb. Ende X, 2 Mal eingeleitet in d. 37. Woche(Nr.3 u. 9), $1, \quad, \quad$ ind.40. , , (Nr. 15).

Welches sind nun in diesen sieben Fällen die Erfolge der künstlichen Frühgeburt?

Nach wiederholtem

Absterben

Ende VII.-VIII. Frühgeb. in der 28. W., Nr. 14: Leb. Kn. †n. $1 \%$

37. W., Nr. 8: 6. Schw. Lebend. Mädch. 7 Pfd. 18“. 7. Schw. Lebend. Knabe. $7^{1 / 2}$ Pfd. $18^{1 / 2}{ }^{16}$.

37. W., Nr. 10: Leb. Kn.

$$
\begin{aligned}
& " \quad " \quad " \quad \text { " } "\left\{\begin{array}{l}
\mathbf{5}^{\mathbf{3}} \mathbf{4}_{\mathbf{4}} \text { Pfd. ,Blieb } \\
\text { mit der Mutter }
\end{array}\right. \\
& \text { 37. W., Nr. 12: Leb. Kn. }
\end{aligned}
$$

Sehen wir von dem in der 28. Woche entwickelten Kinde ab (Fall 14 der 2. Tabelle), da dessen Tod jedenfalls bald zu erwarten war, so wurden im 10. Monate in sechs Fällen sieben lebende Kinder durch die künstliche Frühgeburt erhalten. Von diesen starb das erst in der 40. Woche entwickelte schon nach zwei Tagen an Lungenentzündung (Nr. 15), und eines (Nr. 12) wurde bald von einem syphilitischen Exanthem ergriffen, von dem es jedoch geheilt wurde. Später soll jedoch auch dieses Kind, wie ich einer Notiz bei Krause (l. c. S. 248) entnehme, gestor- 
ben sein. Rechnen wir mithin diese beiden ab, so bleiben noch fü $\mathrm{nf}$, von denen wir bestimmt wissen, dass sie lebend geboren wurden. Hierzu kommen aber noch nach den allgemeinen Angaben aus den Fällen Denman's, Simpson's, Kilian's und Dubourge's sechs lebend entwickelte Früchte. Es resultiren demnach aus 13 verwerthbaren Fällen ${ }^{\mathbf{1}}$ ) von 14 Mal eingeleiteter Frühgeburt 14 lebend geborene Kinder, von denen 3 kürzere oder spätere Zeit nach der Geburt gestorben sind; oder lassen wir das in der 28. Woche geborene Kind als kaum lebensfähig weg, so wurden durch 13 gegen Ende der Schwangerschaft eingeleitete Frübgeburten 13 lebende Kinder geboren, von denen eines später starb, wahrscheinlich in Folge von Syphilis, und das andere an Lungenentzïndung durch intrauterine Athmung in Folge von Stenose der Nabelvene. Von dem letzteren lässt sich als ziemlich gewiss annehmen, dass, wenn es im Beginne der drohenden Symptome des Absterbens oder, wie die anderen, schon in der 37. und nicht erst in der 40. Woche entwickelt worden wäre, es jedenfalls eine bessere Lebenskraft gehabt und fortgelebt hätte. Es würde dann von den 13 lebend geborenen Früchten nur ein Todesfall zu verzeichnen sein.

Damit soll nun aber nicht gesagt sein, dass die anderen 11 Kinder sämmtlich am Leben blieben. Denn leider erfahren wir, worauf es gerade ganz besonders ankommt, ausserordentlich wenig über das weitere Schicksal der Früchte. Von dem einen heisst es, dass es kräftig gedieh; und von dem anderen, dass es mit der Mutter gesund blieb; Notizen, die sich vielleicht auch nur auf die ersten 14 Tage des Lebens beziehen. Wenn darum diese negativen Angaben sehr zu beklagen sind, so darf man doch die Vermuthung nicht ohne Weiteres zurückweisen, dass jene elf eine Zeit lang am Leben gebliebenen Kinder auch um desswillen von Krankheit, zumal von den Zeichen der Lues frei blieben, als gerade dessen z. B. von dem sonst so ausführlichen Simpson keine Erwähnung geschieht.

Entschuldigen wir bei den überhaupt so seltenen Fällen von habituellem Absterben und künstlicher Frühgeburt die ungenügende Beschreibung der seiner Zeit zuerst beobachteten Fälle, so erfordert immerhin das Resultat der durch 14 Frühgeburten 14 lebend geborenen Kinder, von denen vermuth-

1) Nr. 13 kann nicht mit gerechnet werden, da jede Notiz über das Kind fehlt. 
lich 11 längere Zeit am Leben blieben, die grösste Beachtung.

In zwölf Fällen blieben die Mütter gesund; in den drei übrigen Fällen ist nichts darüber angegeben.

Ueber die Geburtsdauer berichten nur sieben Fälle. Operationsverfahren, Geburtsdauer und Befunde des Kindes ergeben folgende Zusammenstellung:

\begin{tabular}{|c|c|c|c|}
\hline Operation & Zeit & Dauer & Kind. \\
\hline $\begin{array}{c}1 \text { Fall (Nr. 15), Krause'sche Me- } \\
\text { thode allein }\end{array}$ & 40. Woche & 3/4 Tag & $\begin{array}{l}\text { Lebend. Kn. } † \mathrm{p} . \\
\quad 2 \text { Tage. }\end{array}$ \\
\hline $\begin{array}{r}1 \text { Fall(Nr. 14), Krause's u. Cohen's } \\
\text { Methode, später Col- } \\
\text { peurynter . . . }\end{array}$ & 28. Woche & $1 \% \mathrm{Tag}$ & $\begin{array}{l}\text { Lebend., }+ \text { p. } 11 / 2 \\
\text { Stunden. }\end{array}$ \\
\hline $\begin{array}{r}4 \text { Fälle (Nr. 3, 8, 9), Pressschwamm, } \\
\text { (einmal danach Bus ch's }\end{array}$ & & & \\
\hline Dilat.)..... & 37. Woche & $1-1 \frac{1}{2} \mathrm{~T}$ & $\begin{array}{l}\text { Lebende, } \mathrm{kräf}- \\
\text { tige Kinder. }\end{array}$ \\
\hline $\begin{array}{r}1 \text { Fall (Nr. 10), } 35 \text { Douchen, später } \\
\text { Sprengung der Blase }\end{array}$ & 37. Woche & 10 Tage & $\begin{array}{l}\text { L e b e n d, blieb } \\
\text { mit der Mutter } \\
\text { gesund. }\end{array}$ \\
\hline
\end{tabular}

Hierzu kommt noch, leider ohne Angabe der Geburtsdauer: 1 Fall (Nr. 12), 34 Douchen. . . $\left|\begin{array}{c}\text { circa } \\ 37 . \text { Woche }\end{array}\right| ? \quad \mid \begin{gathered}\text { Lebendes K., spä- } \\ \text { ter syphilitisch } \\ \text { und gesorben. }\end{gathered}$

Bemerkenswerth ist endlich noch aus dem Falle 14 (DöbnerScanzoni), dass auf die 6. Schwangerschaft, welche in der 28. Woche küstlich unterbrochen wurde, noch eine Schwangerschaft folgte, welche wieder von selbst in der 37. Woche mit der Geburt einer macerirten Frucht endete. Bei der Frau fand sich nach ausdrücklicher Angabe keine Spur von Syphilis, sondern hochgradigste Anämie.

Und ebenso interessant ist es, dass bei einer Frau (Nr. 8) wegen habituellen Absterbens die künstliche Frühgeburt $2 \mathrm{Mal}$ nach einander angewendet wurde, indem nach fünfmaligem $\mathrm{Ab}$ sterben Mitte des 10. Monates die 6. und 7. Schwangerschaft zu 
Anfang des 10. Monates künstlich mit bestem Erfolge unterbrochen wurde.

Diese wenigen, aber ziemlich unter sich übereinstimmenden Beobachtungen lassen sich in folgenden kurzen Sätzen ausdrücken:

In den meisten Fällen fiel das wiederholte (zwei-, fünfmalige) Absterben der Früchte in den letzten Monat der Schwangersehaft.

Die in der nächsten Schwangerschaft dieser Fälle eingeleitete Frühgeburt brachte, ob im Anfange oder gegen Ende des 10. Monates eingeleitet, stets lebende Kinder zur Welt. Im ersteren Falle aber blieben diese, weil circa $1-2$ Wochen vor dem gewöhnlichen Termine des Absterbens entwickelt, jedenfalls alle längere Zeit am Leben, mit Ausnahme eines später an Syphilis erkrankten; im letzteren Falle dagegen starb die Frucht, offenbar weil erst nach Beginn der Symptome des Absterbens, mithin zu spät entwickelt, schon nach wenigen Tagen.

Nur in einem Falle fiel das wiederholte Absterben in Folge von Anämie der Mutter auf den 7. resp. 8. Monat.

Die in diesem Falle bei der nächsten Schwangerschaft entsprechend sehr früh (in der 28. Woche) eingeleitete Geburt entwickelte ein lebendes Kind, das jedoch nur 1\%/2 Stunden lebte.

Die meisten Fälle berichten von den Mïttern und geben an, dass sie gesund und wohl blieben.

Es bedarf gewiss kaum des Hinweises darauf, dass die Erfolge der künstlichen Frühgeburt wegen habituellen Absterbens in jenen obigen, wenn auch nur wenigen Fällen ganz unleugbare sind, und es würden dieselben gewiss sehr angethan sein, für das in Rede stehende Operationsverfahren unbedingt einzutreten.

Noch ist aber ein wichtiger Einwurf, den wir erwarten müssen, zu berücksichtigen, der sich aus dem. Vergleiche mehrerer Fälle aus der I. und II. Tabelle ergiebt, dass nämlich bei einer Reihe von Frauen nach vielmaligem Absterben a uch ohne die künstliche Frühgeburt lebende Kinder erzielt worden sind. Wenn dem so ist, geräth da nicht sofort die Einleitung der Frühgeburt als unnöthiger Eingriff in Misscredit? Sehen wir uns aber diese Fälle etwas genauer an und fragen vor Allem, was jedenfalls von grösstem Belang ist, nach der eventuellen anderen Therapie, die jenes Operationsverfahren unnöthig machte, so verweise ich aus Tabelle I auf die NNr. 2, 3, 5, 6. In Nr. 2 hatte die Frau in sechs Jahren vier Kinder in der 33. Woche geboren. Sie enthielt sich hierauf zwei Jahre des Beischlafes, und trug danach 
ein lebendes Kind aus. In Nr. 3 hatte die Frau in sieben Jahren. sieben Kinder im 7. Monate todt geboren. Wegen Krankheit des Mannes unterblieb dann zwei Jahre der Coitus. Hierauf gebar sie von demselben Manne ein reifes lebendes Kind. In Nr. 6 war eine Frau in den ersten neun Jahren der Ehe sieben Mal 14 Tage vor der Reife mit todten Früchten niedergekommen. Hierauf wurde sie drei Jahre nicht schwanger und gebar danach noch drei reife lebende Kinder. Endlich hatte in Nr. 5 eine schwächliche Frau fünf Mal im 8. Monate todte Früchte zur Welt gebracht. Während der 6. Schwangerschaft brauchte sie eine kräftigende Cur, worauf sie dann das Kind austrug.

Die absichtliche oder unabsichtliche Therapie in diesen Fällen war also Ruhe und Erholung der Sexualorgane und Kräftigung des Gesammtorganismus. War diese Therapie eine zweckmässige oder hätte sie von der künstlichen Frühgeburt ersetzt werden können? In Nr. 2, 3 und 5 sicherlich nicht. Hier waren die Kinder im 7, resp. 8. Monate immer abgestọrben; es hätte dann die Geburt entweder in der letzten Schwangerschaft oder in einer eventuellen neuen noch früher eingeleitet werden müssen; und welches Loos hätte dann das Kind getroffen? Wahrscheinlich wäre es lebend geboren worden, aber, wie in Nr. 14, Tab. II, sehr bald wieder gestorben.

Eine solche Annahme ist aber für Nr. 6 und wahrscheinlich auch für Nr. 7 nach Analogie der Beispiele in der II. Tabelle ganz entschieden zurückzuweisen. In beiden Fällen haben die Fraven sieben $\mathrm{Mal}$ in Mitte des 10. Monates todte Kinder geboren, also immer zu derselben Zeit, immer erst am Ende der Schwangerschaft. Hier lässt sich wohl mit aller Bestimmtheit sagen, dass nach vielleicht viermaligem Absterben, wenigstens. also z. B. yon der 5. Schwangerschaft an, die künstliche Frühgeburt zu Anfang des 10. Monates unbedingt am Platze gewesen wäre, und wohl mit grösster Wahrscheinlichkeit lebende und am Leben bleibende Kinder zur Welt gebracht hätte.

Mit anderen Worten: Wenige Fälle von frühzeitigem Abstexben (7. und 8. Monat) sprechen dafür, dass Erholung der Sexualorgane und des Gesammtorganismus eine folgende Schwangerschaft zum Ende gelangen lassen können.

Einige Beobachtungen aber 'von regelmässigem Absterben im 10. Monate befürworten unbedingt die 
Unterbrechung der Schwangerschaft ungefähr zu Anfang des 10. Monates und rersprechen ginstige Resultate für Mutter und Kind.

Nachdem ich somit versucht habe, nach allen möglichen Richtungen und Einwürfen hin die Beobachtungen zu sichten, welche freilich in spärlicher Anzahl die Literatur, soweit sie mir zugänglich war, aufzuweisen hat, wäre es nun an der Reihe, die anfangs gestellte Frage zu beantworten, welche Stellung nimmt nun die künstliche Frühgeburt dem habituellen Absterben der Kinder gegenüber ein?

Dabei kann es sich aber keinesfalls darum handehn, die oben citirten Ansichten der Autoren betreffs des Für und Wider gegenseitig abzuwägen und die Antwort daraus zu entnehmen. Sondern die Frage kanm allein nur so gestellt werden: Vermag die künstliche Frühgeburt den Ursachen des habituellen Absterbens gegenüber Etwas zu leisten?

Und somit rerbinde ich die Endresultate des ersten und zweiten Abschnittes und komme zu folgenden Schlüssen:

1) Dem habituellen Absterben der Früchte können verschiedene Ursachen zu Grunde liegen; nämlich

a) Syphilis der Eltern,

b) Anämie oder Blutanomalieen der Mutter,

c) chronische Gebärmuttererkrankungen und -reizungen,

d) eine allgemeine individuelle Reizbarkeit,

e) ererbte Disposition, und endlich auf Grund einzelner Beobachtungen

f) Veränderungen der Placenta und dęr Nabelschnur, speciell ihrer Gefässe, die nicht auf Syphilis beruhen und vorläufig noch eine dunkle Genese haben.

2) Die rationelle Behandlung des habituellen Absterbens kann nur in der Behandlung dieser Grundursachen liegen.

3) Von diesen sind die vier ersten einer Therapie fähig; sie besteht ad a) in antiluetischer Behandlung, ad b) in Kräftigung des Gesammtorganismus,

ad c) und d) in entsprechender Behandlnng, Kräftigung und Erholung der Sexualorgane,

gegen die beiden letzten Ursachen e und $f$ wird sich therapeutisch schwer ankommen lassen. 
4) Dem entsprechend wäre die logische Folge, dass die künstliche Frühgeburt den vier ersten Ursachen gegenüber zu verwerfen, den zwei letzten aber gegenüber gut zu heissen wäre.

Dem ist aber nicht so; sondern die vier ersten Ursachen sind ihrer Bedeutung nach von einander zu trennen. Denn

5) in Folge elterlicher Lues ist die Frucht bei habituellem Absterben derselben regelmässig inficirt. Mag sie nun in einem früheren (8.) oder späteren (10.) Monate gewöhnlich abgestorben sein, so wird die künstliche Frühgeburt, auch circa zwei Wochen vor dem gewöhnlichen Termine des Absterbens, eingeleitet, natür lich niemals an der Erkrankung der Frucht Etwas ändern, und wird allerdings lebende Kinder zur Welt bringen können, die jedoch nur ein kurzes und elendes Dasein fristen.

Demnach ist betreff's dieses Punktes den Ansichten Martin's, Döbner's, Scanzoni's und Spiegelberg's, der zuletzt noch in der schärfsten. Weise sich darüber ausgesprochen hat, unbedingt beizustimmen, dass das habituelle Absterben der Früchte in Folge von elterlicher Syphilis als Anzeige zur künstlichen Frühgeburt zu verwerfen ist.

In Folge der anderen Ursachen aber ist die Frucht, wie einige Fälle lehren, nicht erkrankt.

6) Darum ist bei jenen anderen Ursachen die künstliche Frühgeburt um so mehr dann zu befürworten, je näher der habituelle Fruehttod - ich betone ausdrücklich - an das Ende der Schwangerschaft fällt. Als günstigster Zeitpunkt ergiebt sich aus einer Reihe von Fällen die Einleitung der Geburt circa 1-2 Wochen ror dem gewöhnlichen Todeseintritte, speciell in der 37. Schwangerschaftswoche.

Als spätester Zeitpunkt erscheint der Anfang der gewöhnlichen Symptome des habituellen Fruchttodes, und als ung ünstigster die Einleitung der Geburt, während diese Symptome schon eine Zeit lang bestehen, auch wenn die Frucht durch den Foetalpuls noch ihr Leben bekundet. (Tab. II, Nr. 15.)

7) Hieran knüpft sich ein Punkt von praktisch wichtigster Bedeutung.

Wird der Arzt $\mathrm{nach}$ einer wiederholten todten Frühgeburt wegen des in Frage stehenden Leidens zu Rathe gezogen, so hat er in der hierauf folgenden Zeit nur eine Behandlung gegen die 
Grundkrankheit einzuleiten, deren Charakter nach dem Vorausgehenden festzustellen sein wird.

Wird er aber zum ersten Male gerufen in der späteren Zeit einer neuen Schwangerschaft, in der sich die Symptome des Absterbens entweder gerade wie früher wieder vorbereiten oder sich nicht zeigen, soll er dann aus rein theoretischen Gründen, dass eigentlich die Grundursache zu behandeln sei oder diesmal vielleicht das Absterben ausbleibe, ein müssiger Zuschauer sein?

Meiner Ansicht nach würde dies der ärgste Missgriff sein. Ein Irrthum beim passivem Verhalten wiegt den Eltern gegenüber hier weit schwerer, als ein Irrthum bei activem.

Darum ist hier in dem regelmässigen Absterben im letzten Monate der Schwangerschaft entschieden eine Anzeige zur Einleitung der Geburt, frühestens von der 37. Woche an, zu erkennen, da ein fast reifes und lebendes, mit den Chancen des Weiterlebens versehenes Kind uns höher stehen muss, als ein vielleicht nur um 1-2 Wochen reiferes $K i n d$, das aber mit der grösseren Wahrscheinlichkeit dem intrauterinen Tode entgegengeht.

Nach diesen Folgerungen ist es geboten, das in dem von mir beobachteten und Eingangs mitgetheilten Falle eingeschlagene Verfahren einer Kritik zu unterziehen.

Zwei Mal waren gegen Ende der Schwangerschaft, sicherlich nicht in Folge von Lues, mit aller Wahrscheinlichkeit aber in Folge von mütterlicher Anämie kräftig entwickelte Früchte todtgeboren worden. Erst am Ende der neuen Schwangerschaft gerufen, fand ich die Frucht noch lebend, aber schon etwas schwächer, jedenfalls in Folge eines Circulationshindernisses, welches sich durch bedeutendes Nabelschnursausen kund gab und später durch eine beträchtliche Stenose der Nabelvene seine Erklärung fand. Seit circa zwei Tagen bestanden die Symptome des Absterbens der Frucht.

Durfte man sich hier vielleicht exspectativ verhalten? Greifen wir z. B. nicht ein durch Wendung oder Zange bei vorgefallener, schwächer pulsirender Nabelschnur, um noch ein lebendes Kind zu erhalten? Und hier sollten wir unthätig bleiben?

Hier erschien es als Pflicht, so schnell wie möglich die Geburt einzuleiten; und ich glaube behaupten zu können, dass die allerdings noch lebend geborene, aber nach zwei Tagen gestorbene Frucht selbst auf das Deutlichste zeigt, dass sie gerade so der Er- 
stickung nahe war, wie Früchte mit Compression der Nabelschnur, und sicher bei exspectativem Verhalten erstickt wäre.

Nur wenige Tage früher oder schon zu Anfang des zehnten Monates gerufen, würde ich entweder sofort mit Beginn der Absterbesymptome oder schon ein bis zwei Wochen früher mit vollem Rechte die Frühgeburt eingeleitet und wohl mit der grössten Wahrscheinlichkeit ein relativ kräftigeres und lebend bleibendes Kind entwickelt haben.

Wenn ich mich jetzt zum Schlusse wende, so weiss ich selbst sehr wohl, dass ich in diesen Betrachtungen eines der schwersten geburtshülflichen Kapitel berührt und mit nur einer kleinen Zahl von Beobachtungen bestimmte Sätze aufgestellt habe. Es bedarf aber wohl kaum der Erwähnung, dass diese Thesen, da sie sich auf nur geringe Erfahrungen stützen, nicht unfehlbare sein wollen. Und auch wenn das habituelle Absterben durch andere Ursachen als Lues eine seltene Erscheinung ist, so kann dieser Umstand dem fraglichen Leiden die praktische Tragweite nicht entziehen, und erfordert dieselbe Beachtung, welche wir z. B. schweren Erkrankungen der Mutter zollen, die ebenfalls die Unterbrechung der Schwangerschaft nöthig machen.

So übergebe ich diesen Versuch, die künstliche Frühgeburt dem habituellen Absterben der Früchte gegenüber in das rechte Licht zu stellen, der Beurtheilung der Fachgenossen, und würde mich belohnt wissen, damit eine Anregung zur Veröffentlichung und Kritik ähnlicher Fälle gegeben zu haben. 